\title{
Interdecadal Change in the Effect of Spring Soil Moisture over the Indo-China Peninsula on the Following Summer Precipitation over the Yangtze River Basin
}

\author{
ChujIE GaO \\ College of Oceanography/Key Laboratory of Ministry of Education for Coastal Disaster and Protection/Key Laboratory of \\ Marine Hazards Forecasting, Ministry of Natural Resources, Hohai University, and Southern Marine Science and \\ Engineering Guangdong Laboratory (Zhuhai), and Key Laboratory of Meteorological Disaster, Ministry of Education/ \\ Collaborative Innovation Center on Forecast and Evaluation of Meteorological Disasters, Nanjing University of Information \\ Science and Technology, Nanjing, and State Key Laboratory of Loess and Quaternary Geology, \\ Institute of Earth Environment, Chinese Academy of Sciences, Xi'an, China
}

GEN LI

College of Oceanography/Key Laboratory of Ministry of Education for Coastal Disaster and Protection/Key Laboratory of Marine Hazards Forecasting, Ministry of Natural Resources, Hohai University, Nanjing, and Southern Marine Science and Engineering Guangdong Laboratory (Zhuhai), China

\section{HAISHAN CHEN}

Key Laboratory of Meteorological Disaster, Ministry of Education/Collaborative Innovation Center on Forecast and Evaluation of Meteorological Disasters, Nanjing University of Information Science and Technology, Nanjing, China

\section{HONG YAN}

State Key Laboratory of Loess and Quaternary Geology, Institute of Earth Environment, Chinese Academy of Sciences, Xi'an, China

(Manuscript received 9 October 2019, in final form 4 May 2020)

\begin{abstract}
The land surface energy exchange over the Indo-China Peninsula (ICP) is important for regulating regional weather and climate. This work investigates the effect of spring soil moisture (SM) over the ICP on the following summer precipitation over the Yangtze River basin (YRB) during 1961-2010. The results show that the spring SM over the ICP has a significant negative correlation with the following summer YRB precipitation. However, this relationship experiences an obvious interdecadal change with a much stronger correlation in the epoch before the early 1990s (1961-91) than in the later decades (1992-2010). In spring, an abnormally lower SM over the ICP could induce less surface evapotranspiration, increasing local temperature until the summer. Before the 1990s, the resultant anomalous ICP heating raises the local geopotential height, resulting in an excessive westward extension of the western Pacific subtropical high (WPSH). Accordingly, the enhanced southwesterly summer monsoon would transport more moisture to the YRB, intensifying the meiyu front and local precipitation. In the early 1990s, the East Asian summer monsoon underwent an abrupt change with an interdecadal westward extension of the climatic WPSH. Consequently, the similar abnormal ICP surface heating induced by the anomalous SM would have different influences on the monsoonal circulation, causing a much weaker effect on the YRB precipitation in the recent decades.
\end{abstract}

\section{Introduction}

Droughts and floods over the Yangtze River basin (YRB) are major natural disasters in China (Wei et al. 2012), which often cause serious damages to the national

Corresponding author: Gen Li, ligen@hhu.edu.cn economy and people's lives. Summer precipitation over the YRB exhibits large interannual variability (Jiang et al. 2010; Gao et al. 2019) and is prone to regional droughts/floods. For example, in the summer of 1998, a severe flood occurred over the YRB, and caused economic losses of more than $\$ 30$ billion, affecting more than 15 million people (Huang et al. 1998). Thus, it is of great 
scientific and socioeconomic importance to explore the causes of summer precipitation anomalies over the YRB.

Summer precipitation over the YRB is closely linked to the intensity and advancement of the East Asian monsoon (Ding and Chan 2005), and it is an important part of the East Asian monsoonal precipitation (Gao et al. 2015; Zhang and Zhou 2015). The strong southwesterly monsoon in summer brings a large amount of water vapor and precipitation to the YRB from the South China Sea. The establishment and evolution of the East Asian summer monsoon are highly associated with the western Pacific subtropical high (WPSH). As shown by $\mathrm{He}$ et al. (2001), the summer precipitation over the YRB is highly associated with the area, intensity, and location of the WPSH, which could guide the southwesterly monsoon bringing water vapor from the Bay of Bengal, the western Pacific, and the South China Sea to the eastern China for the monsoonal precipitation (Wang and Chen 2012).

The East Asian summer monsoon is a result of sealand-atmosphere interactions. Therefore, the East Asian monsoonal circulation in summer is affected not only by the sea surface thermal condition, but also by the land surface thermal condition. Soil moisture (SM) is one of the most important land factors affecting local thermal condition (Seneviratne et al. 2010; Bellucci et al. 2015). In monsoonal regions, SM anomalies can adjust the surface air temperature by changing the local land surface evapotranspiration and thus affect the large-scale circulation and monsoonal precipitation (Douville et al. 2001; Douville 2002). Previous studies have shown that the abnormal land surface heating due to the anomalous SM can influence the large-scale summer monsoon circulation, leading to abnormal precipitation over the YRB (Zuo and Zhang 2007; Meng et al. 2014; Liu et al. 2017). For instance, Zhang and Zuo (2011) found that the spring SM anomaly from the YRB to northern China changes the land-sea thermal contrast, and in turn affects the East Asian monsoon system, resulting in anomalous summer precipitation over the YRB. Liang and Chen (2010) showed that the abnormal spring SM in South China also exhibits an evident impact on summer precipitation over the YRB through affecting the surface temperature and the monsoon system. The results from Zhan and Lin (2011) and Zuo and Zhang (2016) further verify that the summer precipitation over the YRB may be closely related to the spring SM anomalies over the East Asian monsoon regions.

The Indo-China Peninsula (ICP) is located in the upper region of the East Asian summer monsoon, which plays an important role in the monsoon system. The results from the model experiments demonstrated that the East Asian summer monsoon would be greatly changed if the ICP continent were replaced by the ocean
(Chen and Chen 1991). Jin et al. (2006) further indicated that the thermal contrast between the ICP and the western Pacific is crucial to the formation of the East Asian monsoon system. Wang and Qian (2001) also found that the continuous sensible heating over the ICP promotes the onset of the East Asian summer monsoon. This sensible heating leads to a warmer center in the lower atmosphere near the ICP and the strong horizontal temperature and geopotential height gradients, strengthening the southwesterly monsoon (Zhang and Qian 2002). Therefore, the surface thermal condition over the ICP has obvious effects on the East Asia summer monsoon. Recently, the findings from Ma et al. (2018) and Gao et al. (2019) have demonstrated that the SM over the ICP exhibits a significant impact on the formation and development of the East Asian summer monsoon by affecting the local thermal condition. In addition, Yang et al. (2019) suggested that the spring SM over the southeastern ICP is a reliable predictor of extreme heat events over the YRB. These results imply that the spring SM over the ICP might exert large influences on the following summer climate over the YRB.

We also notice that the East Asian summer monsoon system has undergone an abrupt change around the early 1990s with an interdecadal westward extension of the climatic WPSH (Ding et al. 2009; Gao et al. 2015). In particular, before the 1990s, the precipitation over the YRB was significantly positively correlated with the intensity of the WPSH, but after that the positive correlation weakened rapidly (Gao et al. 2015). Thus, our issue is here proposed: Does the effect of spring SM over the ICP on the following summer precipitation over the YRB experience an interdecadal change in the early 1990s?

This study explores the effect of spring SM over the ICP on the following summer precipitation over the YRB during 1961-2010. The present analyses find that the spring SM over the ICP has a significant negative correlation with the following summer precipitation over the YRB. Nevertheless, under the background of climate change, this relationship is much stronger in the epoch before 1992 (1961-91) than in the recent decades (19922010). Accompanied by an interdecadal westward extension of the climatic WPSH, the similar abnormal surface heating induced by the anomalous ICP SM over the ICP has rather different effects on the East Asian monsoonal circulation and the precipitation over the YRB before and after the early 1990s. These results have important implications for the prediction of summer climate over East Asia in the context of climate change.

The rest of this paper is organized as follows. Section 2 introduces the datasets and methods used in this study. Section 3 reveals the interdecadal change in the relationship between the spring SM over the 
ICP and the following summer precipitation over the YRB. Section 4 investigates the local thermal effect of SM over the ICP. Section 5 documents the interdecadal change in the responses of monsoonal circulation and precipitation to SM anomalies over the ICP. The conclusions and discussions are given in section 6 .

\section{Datasets and methods}

In this study, the SM data with a horizontal resolution of $1^{\circ} \times 1^{\circ}$ are from the Global Land Data Assimilation System (GLDAS) V2.0 (Rodell et al. 2004). This dataset provides the moisture information at four soil layers (i.e., 0-10, 10-40, 40-100, and 100$200 \mathrm{~cm}$ ) and has been used in many studies of landatmosphere interactions over East Asia (e.g., Wu and Zhang 2013; Cheng et al. 2015; Cheng and Huang 2016). We only use the surface-layer $(0-10 \mathrm{~cm})$ data, which are more sensitive to the atmospheric forcing and in turn provide direct feedbacks on the atmosphere (Zuo and Zhang 2007; Dirmeyer 2011). In addition, we also examine the GLDAS upward land surface latent heat flux (used as evapotranspiration) and surface air temperature data.

The monthly sea surface temperature (SST) data are from the Hadley Centre Sea Ice and SST dataset (Rayner et al. 2003). The tropospheric air temperature, geopotential height, wind, and humidity fields are collected from the Japanese 55-year Reanalysis (JRA-55; Kobayashi et al. 2015). The observed precipitation and temperature data are gathered from the Climatic Research Unit (CRU) at the University of East Anglia. The present study period spans from 1961 to 2010, covering the shared time period of all the datasets.

As there is little water vapor above $300 \mathrm{hPa}$, the tropospheric water vapor flux is vertically integrated from 300 to $1000 \mathrm{hPa}$, and the equation is as follows:

$$
Q=\frac{1}{g} \int_{\mathrm{Pt}}^{\mathrm{Ps}} q \mathbf{V} d P
$$

where $Q$ is the water vapor flux; $g, q$, and $\mathbf{V}$ are the acceleration of gravity, specific humidity, and the horizontal wind vector, respectively; and $\mathrm{Pt}$ and Ps denote the pressure levels of 300 and $1000 \mathrm{hPa}$, respectively.

To examine whether the anomalies of wind or specific humidity are dominating the moisture transport, the water vapor flux is divided to the dynamic and thermodynamic processes (Seager et al. 2010). When the wind and specific humidity can be expressed as the sums $\left(\mathbf{V}=\mathbf{V}_{A}+\mathbf{V}^{\prime}\right.$ and $\left.q=q_{A}+q^{\prime}\right)$ of climatic mean states $\left(\mathbf{V}_{A}\right.$ and $\left.q_{A}\right)$ and interannual anomalies $\left(\mathbf{V}^{\prime}\right.$ and $q^{\prime}$ ), Eq. (1) can be transformed into

$$
\begin{aligned}
\frac{1}{g} \int_{\mathrm{Pt}}^{\mathrm{Ps}} q \mathbf{V} d P= & \frac{1}{g} \int_{\mathrm{Pt}}^{\mathrm{Ps}}\left(q_{A}+q^{\prime}\right)\left(\mathbf{V}_{A}+\mathbf{V}^{\prime}\right) d P \\
= & \frac{1}{g} \int_{\mathrm{Pt}}^{\mathrm{Ps}} q_{A} \mathbf{V}_{A} d P+\frac{1}{g} \int_{\mathrm{Pt}}^{\mathrm{Ps}} q^{\prime} \mathbf{V}_{A} d P+\frac{1}{g} \int_{\mathrm{Pt}}^{\mathrm{Ps}} q_{A} \mathbf{V}^{\prime} d P \\
& +\frac{1}{g} \int_{\mathrm{Pt}}^{\mathrm{Ps}} q^{\prime} \mathbf{V}^{\prime} d P
\end{aligned}
$$

where $(1 / g) \int_{\mathrm{Pt}}^{\mathrm{Ps}} q_{A} \mathbf{V}_{A} d P,(1 / g) \int_{\mathrm{Pt}}^{\mathrm{Ps}} q_{A} \mathbf{V}^{\prime} d P$, and $(1 / g) \int_{\mathrm{Pt}}^{\mathrm{Ps}}$ $q^{\prime} \mathbf{V}_{A} d P$ are the climatic state and the dynamic and thermodynamic processes of the water vapor flux, respectively; $(1 / g) \int_{\mathrm{Pt}}^{\mathrm{Ps}} q^{\prime} \mathbf{V}^{\prime} d P$ is a neglected small term (Gao et al. 2019). The dynamic [(1/g) $\left.\int_{\mathrm{Pt}}^{\mathrm{Ps}} q_{A} \mathbf{V}^{\prime} d P\right]$ and thermodynamic $\left[(1 / g) \int_{\mathrm{Pt}}^{\mathrm{Ps}} q^{\prime} \mathbf{V}_{A} d P\right]$ terms denote the contributions of the wind and specific humidity anomalies to the moisture transport, respectively.

\section{Interdecadal change in the relationship between the spring ICP SM and the following summer precipitation over the YRB}

Figure 1 illustrates the correlation coefficients of the spring (March-May) SM averaged over the ICP $\left(10^{\circ}-\right.$ $25^{\circ} \mathrm{N}, 95^{\circ}-106^{\circ} \mathrm{E}$ ) with the following summer (JuneAugust) precipitation over eastern China. Over South China, the interannual summer precipitation has a significant $(p<0.1)$ positive correlation with the preceding spring ICP SM, while the correlation turns to negative in a larger coverage over the YRB (Fig. 1a). Compared with South China, the negative correlation region over the YRB is relatively larger and more evident. We further calculate the summer precipitation anomalies averaged over the YRB $\left(28^{\circ}-33^{\circ} \mathrm{N}, 106^{\circ}-119^{\circ} \mathrm{E}\right.$; boxed area in Fig. 1a) for the period of 1961-2010, and compare them with the preceding spring SM anomalies averaged over the ICP (Fig. 1b). Generally, the interannual SM anomalies over the ICP are opposite to the following summer precipitation anomalies over the YRB with a significant $(p<0.01)$ negative correlation of -0.40 . This indicates that when the ICP is abnormally drier in spring, there is excessive precipitation over the YRB for the following summer, and vice versa. However, we notice that this relationship has been unstable during the past 50 years (Fig. 1b). In the early period, the negative 21-yr moving correlation coefficients are statistically significant $(p<0.01)$ until 1981 (the correlation coefficient in 1981 is the result for the period of 1971-91). Starting from 1982, the moving correlation coefficient exhibits a sharp change, and is not statistically significant during the latest two 

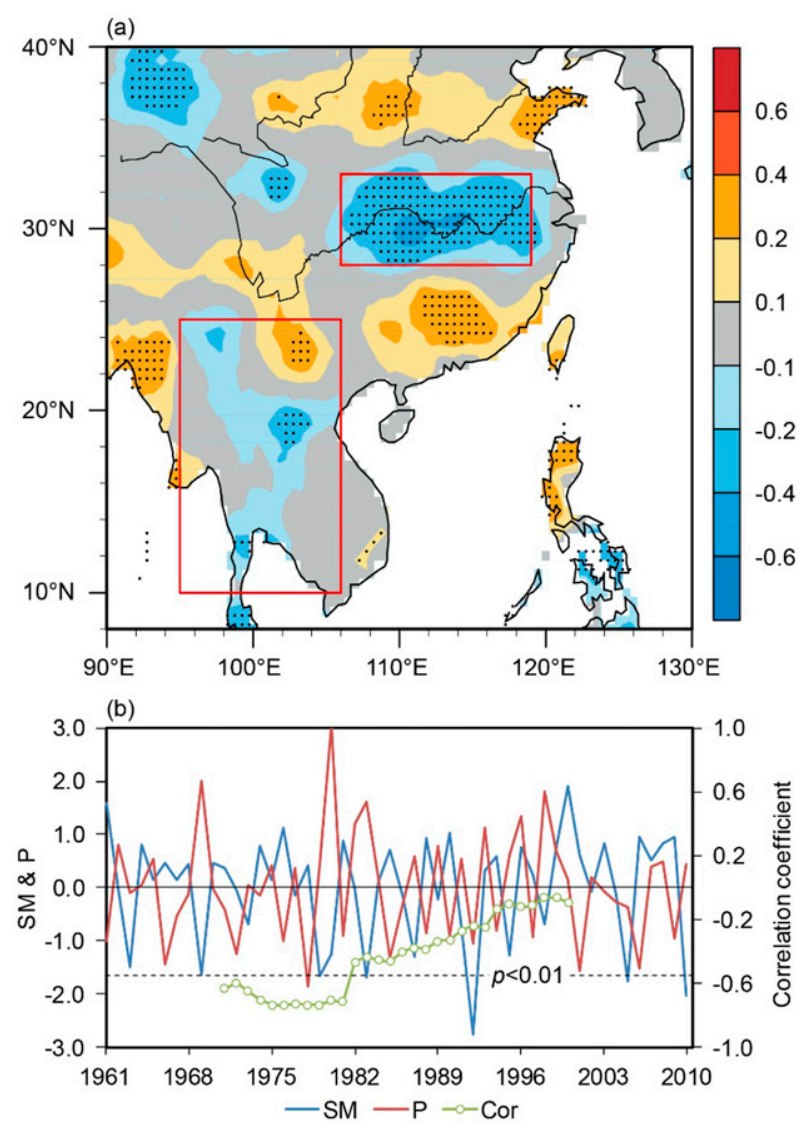

FIG. 1. (a) Correlation coefficients of summer (June-August) precipitation with the preceding spring (March-May) soil moisture (SM) averaged over the Indo-China Peninsula (ICP; $10^{\circ}-25^{\circ} \mathrm{N}, 95^{\circ}-$ $106^{\circ} \mathrm{E}$ ) for the period of $1961-2010$. The grid points with dots are significant with $p<0.1$. (b) Interannual anomalies of the spring SM (blue line) averaged over the ICP and the following summer precipitation ( $P$; red line) averaged over the Yangtze River basin (YRB; $28^{\circ}-33^{\circ} \mathrm{N}, 106^{\circ}-119^{\circ} \mathrm{E}$ ). The green line with circles denotes the 21-yr moving correlation coefficient (Cor) between the SM and $P$. All data are linearly detrended and standardized. The red boxed areas in (a) denote the ICP and the YRB.

decades (Fig. 1b). This suggests that the relationships between the spring SM over the ICP and the following summer precipitation over the YRB have undergone an interdecadal change around the early 1990s with a much stronger negative correlation in the epoch before 1992 (1961-91) than in the more recent decades (1992-2010).

Therefore, we divide the study period into two subperiods: the early period (1961-91) and the late period (1992-2010). Similar to Fig. 1a, Fig. 2 shows the spatial distributions of the correlation coefficients during the two subperiods. The negative correlation over the YRB is dominant and statistically significant $(p<0.1)$ for the early period, and even stronger than that for the whole study period (Fig. 2a). In contrast, the correlation between the spring ICP soil condition and the following summer YRB precipitation for the late period is insignificant (Fig. 2b). Considering that monsoonal precipitation in summer over East Asia might be closely linked to El Niño-Southern Oscillation (ENSO) events (Zhang et al. 2016), the partial correlations after removing the ENSO signals are additionally calculated. In the present work, the sea surface temperature anomalies (SSTA) averaged over the Niño-3.4 region $\left(5^{\circ} \mathrm{N}-5^{\circ} \mathrm{S}, 120^{\circ}-\right.$ $170^{\circ} \mathrm{W}$ ) are employed to denote the ENSO events. Moreover, the SSTA in the previous and subsequent winter (December, January, and February) are used as the ENSO decaying and developing signals, respectively. The correlation coefficients of Niño-3.4 SST anomalies in previous and subsequent winters with the ICP SM in spring are $-0.57(p<0.001)$ and -0.02 , respectively, during the study period (1961-2010). The correlations between the spring ICP SM and summer YRB precipitation before and after removing the effect of the ENSO decaying or developing phases are generally similar (Figs. $2 \mathrm{a}-\mathrm{f}$ ), suggesting that the spring ICP soil condition can affect the summer precipitation over the YRB independently during the early period, regardless of the ENSO effects. Furthermore, the tropical Indian Ocean SSTA induced by ENSO forcing is usually strong in decaying summer and helps sustain the effects of ENSO on the East Asian climate (Xie et al. 2016). Since they are both related to the East Asian summer monsoon climate, the spring ICP SM anomaly and the summer Indian Ocean basin $\left(20^{\circ} \mathrm{N}-\right.$ $\left.20^{\circ} \mathrm{S}, 40^{\circ}-100^{\circ} \mathrm{E}\right) \mathrm{SSTA}$ are closely linked, with a correlation coefficient of $-0.42(p<0.01)$. Figures $2 \mathrm{~g}$ and $2 \mathrm{~h}$ further show the partial correlations after removing summer SSTA of the Indian Ocean basin. Likewise, there is a strong negative correlation between the spring ICP SM and summer precipitation over the YRB during 1961-91, which vanishes during 1992-2010. This also confirms that the effect of spring SM anomaly over the ICP on the following summer precipitation over the YRB is independent of the tropical Indian Ocean basin SST forcing. In addition, the correlation between the spring ICP SM and the summer SSTA over the Indowestern Pacific $\left(0^{\circ}-20^{\circ} \mathrm{N}, 75^{\circ}-125^{\circ} \mathrm{E}\right)$ is high at 0.49 $(p<0.001)$. To remove the possible influence of the Indo-western Pacific SSTA, we calculated the partial correlations after removing the effect of the Indo-western Pacific SSTA as in Fig. 2. The correlations between the spring ICP SM and summer YRB precipitation before and after removing the Indo-western Pacific SSTA are almost the same (figure not shown). This confirms that the effect of spring ICP SM anomaly on the following summer precipitation over the YRB is also independent of the Indo-western Pacific SST forcing. 
(a)

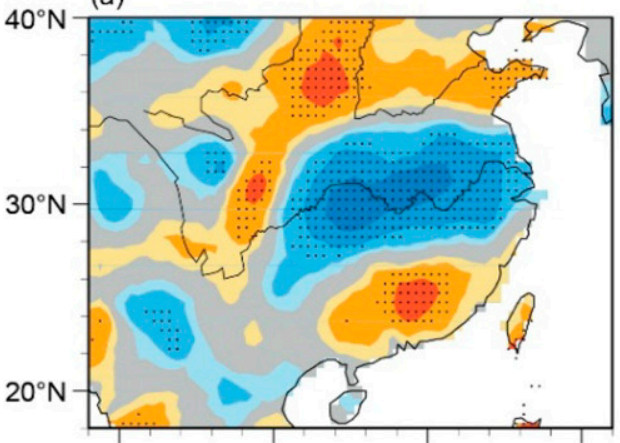

(c)

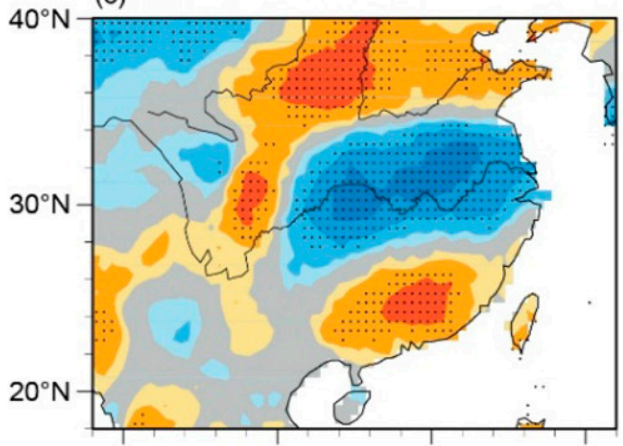

(e)

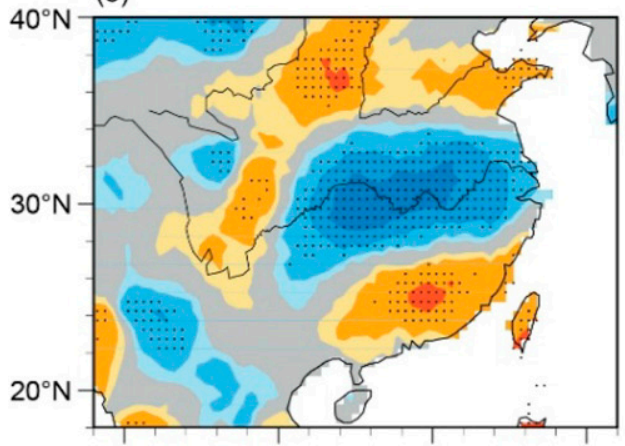

(g)

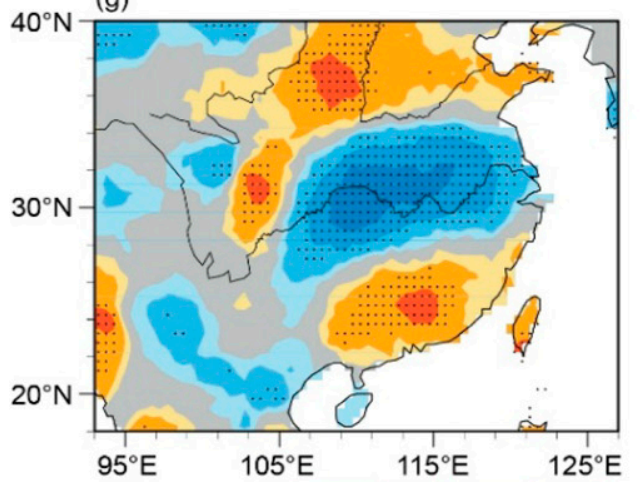

(b)

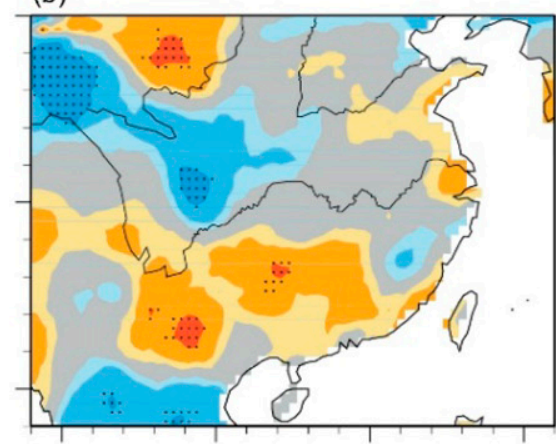

(d)

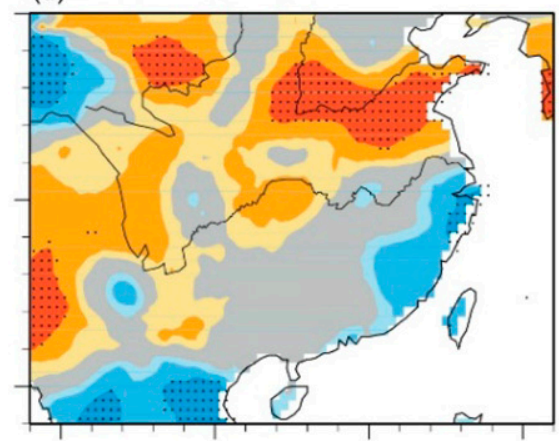

(f)

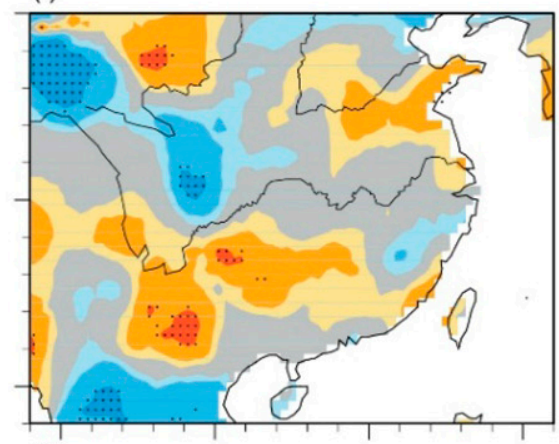

(h)

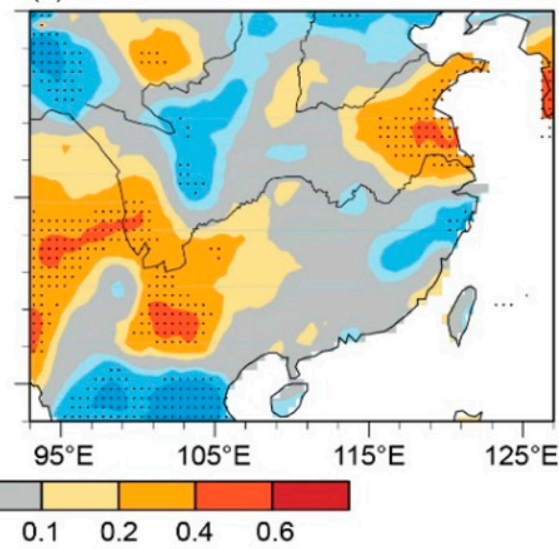

FIG. 2. Correlation coefficients of summer precipitation with the preceding spring SM averaged over the ICP for the periods (a) 1961-91 and (b) 1992-2010. (c)-(h) As in (a) and (b), but for the partial correlation coefficients after removing the parts linearly related to (c),(d) the previous winter (DecemberFebruary) and (e),(f) subsequent winter sea surface temperature (SST) anomalies in the Niño-3.4 region $\left(5^{\circ} \mathrm{N}-5^{\circ} \mathrm{S}, 120^{\circ}-170^{\circ} \mathrm{W}\right)$, and $(\mathrm{g}),(\mathrm{h})$ the summer Indian Ocean basin $\left(20^{\circ} \mathrm{S}-20^{\circ} \mathrm{N}, 40^{\circ}-100^{\circ} \mathrm{E}\right)$ SST anomaly. The grid points with dots are significant with $p<0.1$. All data are linearly detrended. 


\section{Local thermal effect of SM over the ICP}

Previous studies (Zuo and Zhang 2007; Zhan and Lin 2011; Gao et al. 2019) suggested that the abnormal SM in monsoonal regions may regulate the large-scale atmospheric circulation and precipitation by affecting the local land surface evapotranspiration and thermal conditions. In this section, we first look into the local thermal effects of SM over the ICP for the two subperiods of 1961-91 and 1992-2010. The results show that the anomalous thermal conditions induced by the abnormal ICP SM through altering local land surface evapotranspiration are basically similar for the two subperiods.

According to the theory of Dirmeyer et al. (2009), the correlation between SM and evapotranspiration is used to indicate the state of land-atmosphere interactions (SM affecting the atmosphere or the atmosphere affecting SM). Figures $3 a$ and $3 b$ show the correlations between the interannual SM and local evapotranspiration anomalies over the ICP in spring. The positive correlation coefficients mainly dominate this region in both subperiods, implying that SM controls evapotranspiration (e.g., higher SM leads to stronger evapotranspiration). Since the positive correlation between SM and evapotranspiration is a necessary but not sufficient condition of land affecting atmosphere (Dirmeyer 2011), the correlations between evapotranspiration and surface air temperature are further shown in Figs. 3c and 3d. In general, the ICP exhibits a negative evapotranspiration-temperature relationship in both subperiods, which is a sign of the strong land-atmosphere coupling (land states evidently affecting the atmosphere; Seneviratne et al. 2010; Zittis et al. 2013). This means that the strong (weak) evapotranspiration induced by positive (negative) SM anomaly decreases (increases) the local temperature. Indeed, the SM-temperature relationships in spring are negative during both the early and late periods (Figs. 3e,f).

Figure 4 shows the relationships among the areaaveraged SM, evapotranspiration, and surface air temperature over the ICP in spring. During the early period, the SM-evapotranspiration and evapotranspirationtemperature correlation coefficients are 0.85 and -0.63 with a significant level of $p<0.001$ (Figs. 4a,c). This indicates that the SM anomaly can evidently change the evapotranspiration, and in turn the air temperature in the ICP. For example, an abnormally higher SM over the ICP increases the local surface evapotranspiration, which leads to a lower surface air temperature. As a result, the SM and temperature over the ICP in spring are highly correlated negatively (with a correlation coefficient of $-0.69, p<0.001$; Fig. 4e). Compared with the early period, these correlations during the late period are slightly weaker but all statistically significant (Figs. 4b,d,f). In other words, the early stages (i.e., thermal control) of the land surface affecting the atmosphere are generally the same during the two subperiods.

The precipitation variation has always been considered as the primary driving factor of SM anomalies (Piao et al. 2009). The correlation coefficient between regional mean precipitation and SM anomalies in spring over the ICP reaches $0.83(p<0.001)$, which confirms that local precipitation plays a decisive role in controlling SM variations over the ICP. An important characteristic of $\mathrm{SM}$ is the persistent quality of its anomalies (Koster and Suarez 2001; Dirmeyer et al. 2009; Gao et al. 2017, 2019), which is the scientific basis for it being a seasonal predictor of climate states. Figure 5a shows the correlations of monthly SM averaged from the grid points over the ICP with the local mean spring SM during the two subperiods. In both subperiods, the spring SM anomalies over the ICP exhibit strong $(p<0.1)$ positive correlations with the local SM in June and July, suggesting that the abnormal SM states can be sustained to summer. Furthermore, the strong positive correlations between spring and summer SM anomalies over the ICP show that the strong SM memory locates in the west side during the early period, whereas it extends to the southeast during the late period (Figs. 5b,c). Overall, the results suggest that the memory effect of spring SM anomalies over the ICP can persist until the following summer.

To explore the local thermal responses to spring ICP SM anomalies in the two subperiods, we further calculated the regression coefficients of spring and summer observed temperature onto the spring SM anomalies (Fig. 6). During 1961-91, the spring temperature generally rises by more than $0.3 \mathrm{~K}$ when the SM is lower than normal by one standard deviation (Fig. 6a). The abnormal SM continuously affects the temperature in summer by $0.1 \mathrm{~K}$ warmer over the ICP (Fig. 6c). The situation is almost the same during 1992-2010 (Figs. 6b,d). This suggests that the spring SM anomalies can evidently affect the local thermal states over the ICP until the following summer due to the strong memory of SM during both subperiods. This thermal effect of SM may potentially modulate the summer monsoon circulation and precipitation over East Asia, consistent with our recent study (Gao et al. 2019).

\section{Interdecadal changes in the monsoonal circulation and precipitation responses to SM anomalies}

Why do the similar local thermal effects of SM over the ICP result in rather different large-scale monsoonal 
(a)

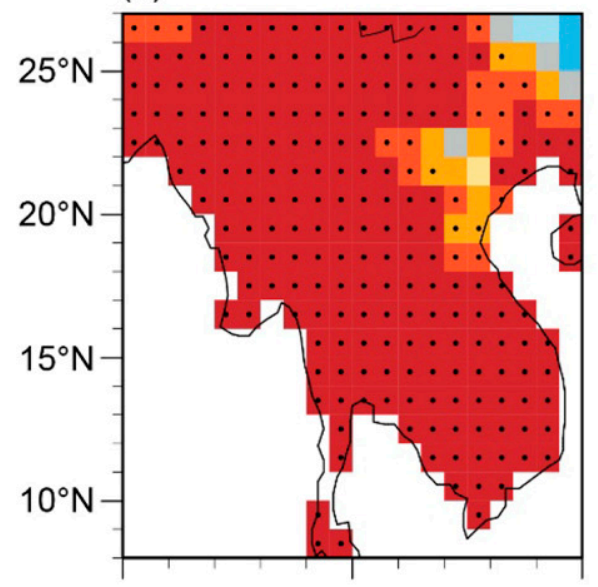

(c)

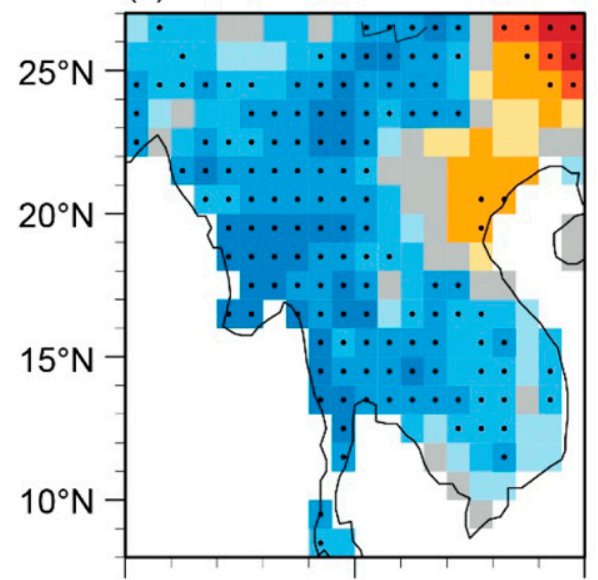

(e)

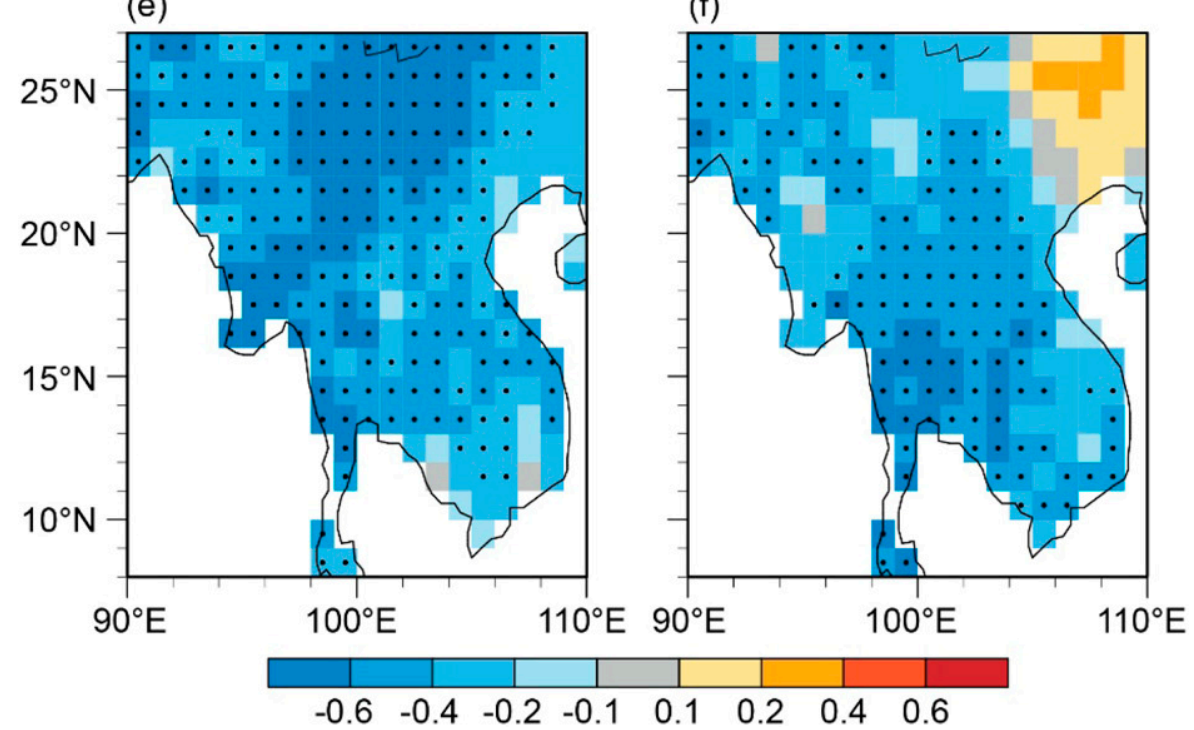

FIG. 3. Correlation coefficients (a) between SM and upward latent heat flux, (c) between upward latent heat flux and surface air temperature, and (e) between SM and surface air temperature at each grid point in spring during 1961-91. (b),(d),(f) As in (a), (c), and (e), but for the period of 1992-2010. All data are linearly detrended. The grid points with dots are significant with $p<0.1$. (b)

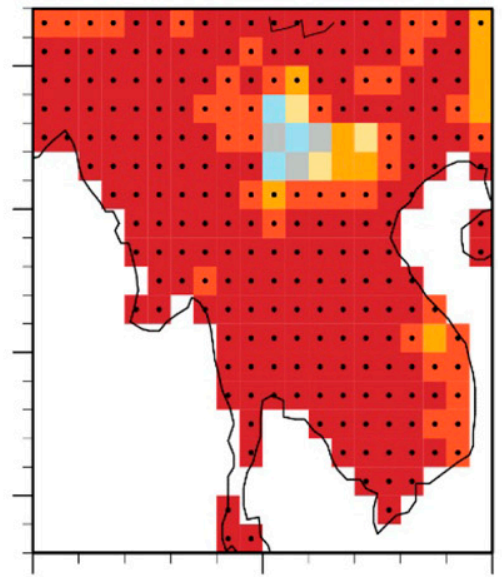

(d)

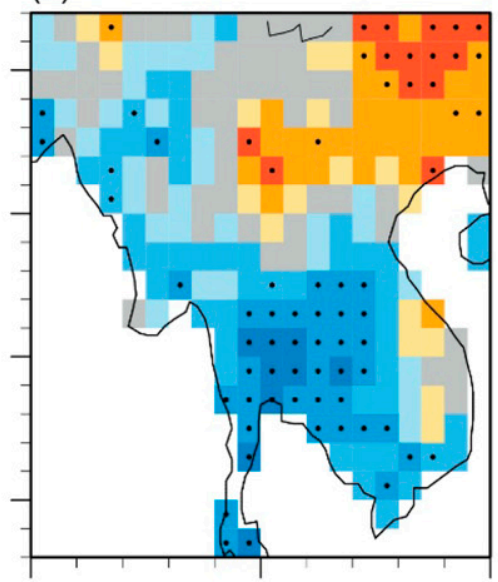

(f) 
(a)

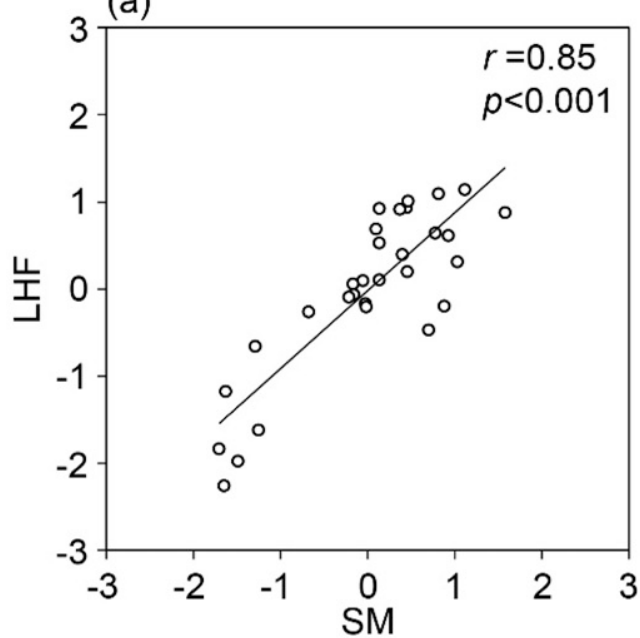

(c)

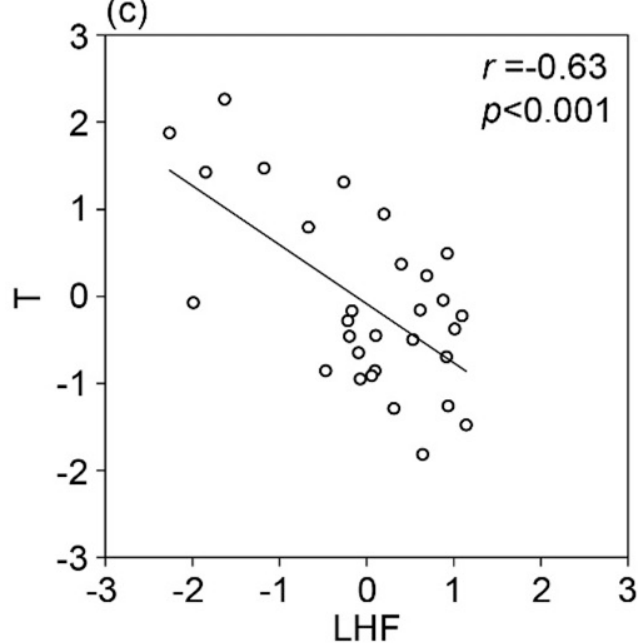

(e)

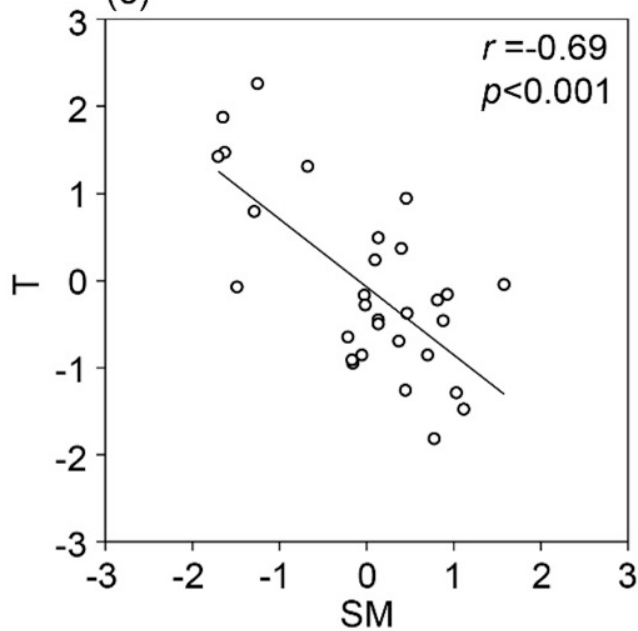

(b)

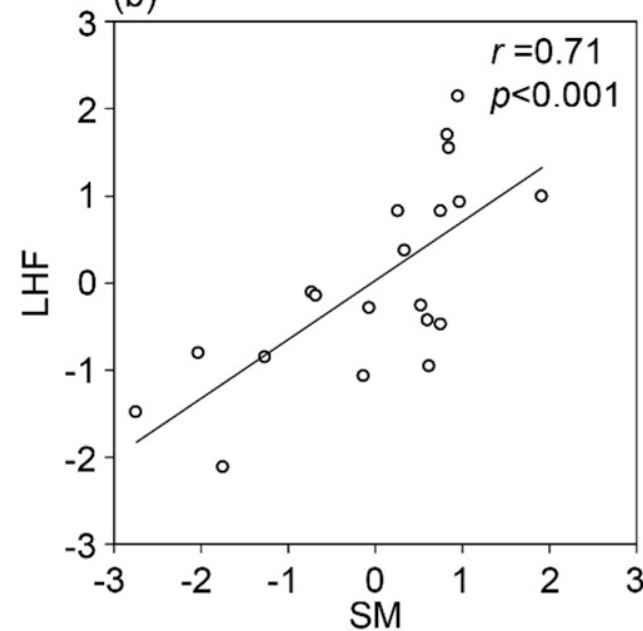

(d)

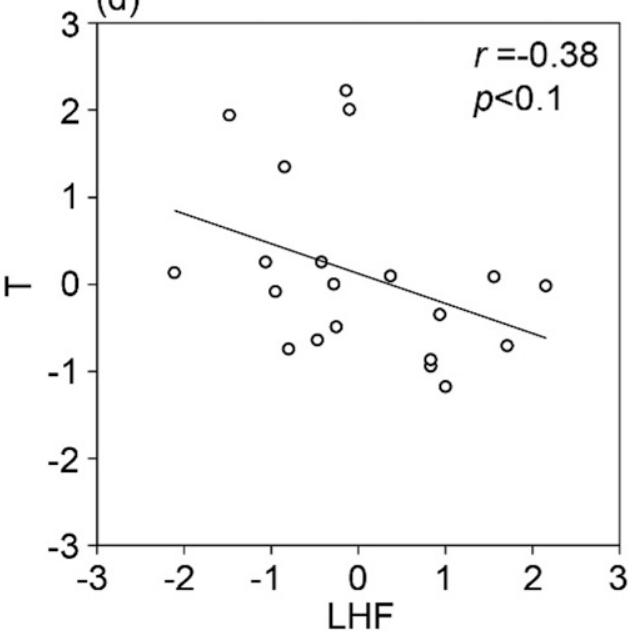

(f)

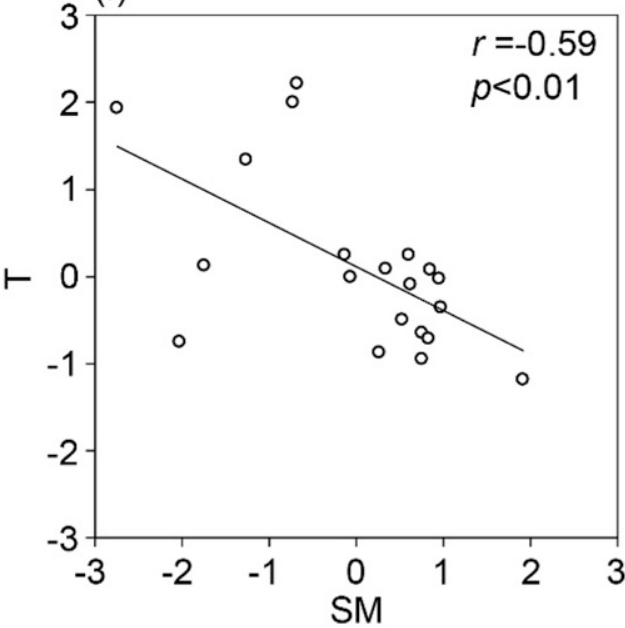

FIG. 4. Relationships (a) between SM and latent heat flux (LHF), (c) between LHF and surface air temperature (T), and (e) between SM and $T$ over the ICP in spring during 1961-91. (b),(d),(f) As in (a), (c), and (e), but for the period of 1992-2010. All data are linearly detrended and standardized. 
(a)

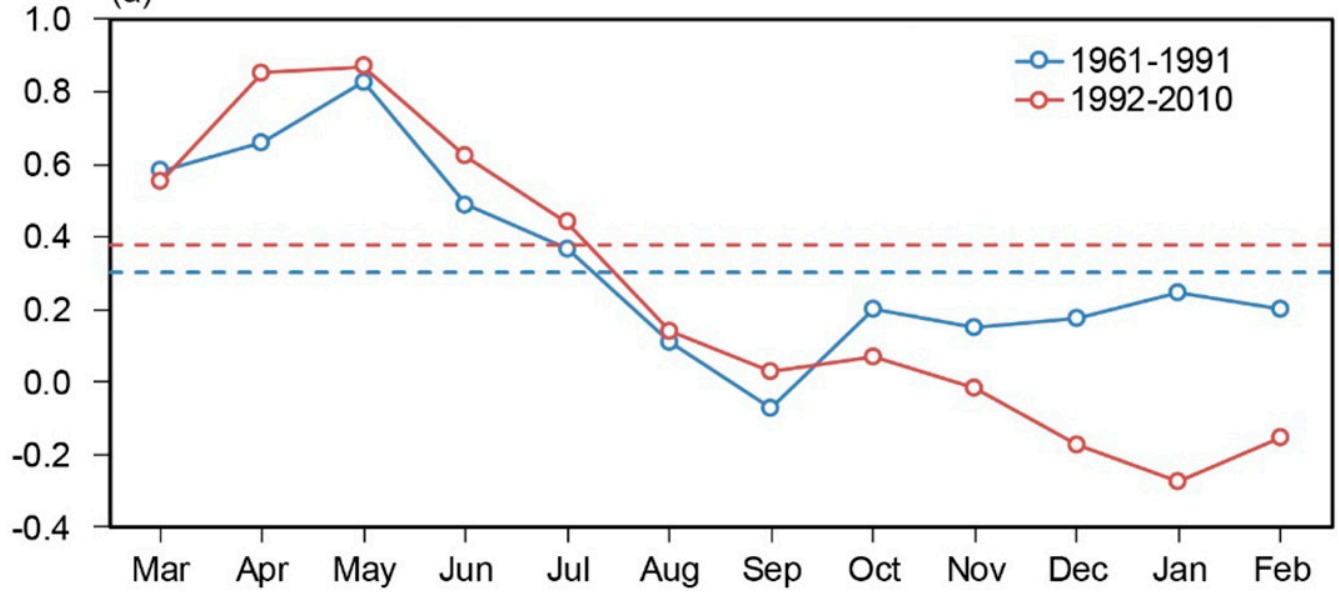

(b)

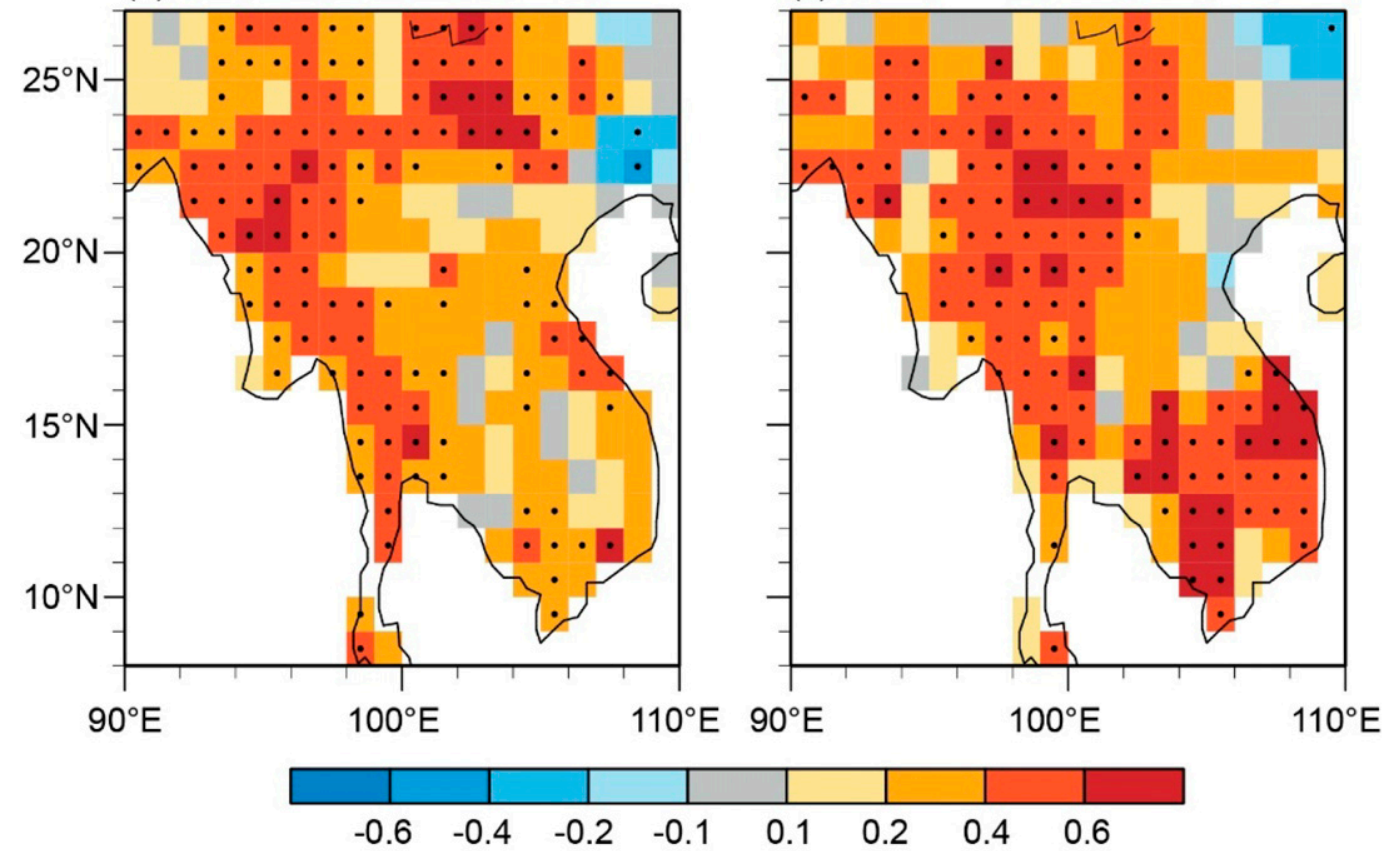

FIG. 5. (a) Correlation coefficients of monthly SM anomalies with the spring SM anomalies averaged over the ICP for the periods of 1961-91 and 1992-2010. The blue and red dashed lines denote the significance level of $p<0.1$ in the two subperiods. (b) Correlation coefficient of spring SM anomalies with the following summer SM anomalies at each grid point for the period of 1961-91.The dots are significant with $p<0.1$. (c) As in (b), but for the period of 1992-2010. All data are linearly detrended.

circulation and precipitation responses in the two subperiods? Actually, around the early 1990s, the East Asian summer monsoon system and summer precipitation in China have undergone an abrupt climate shift with an interdecadal westward extension of the climatological WPSH (Ding et al. 2009; Gao et al. 2015). In such a case, different responses of the large-scale monsoonal circulation and precipitation anomalies to the identical surface heating over the ICP may be expected, similar to the previous results from both the statistical analyses and model sensitivity experiments that identical atmospheric heating over the tropical western North Pacific could induce different responses of the East Asian summer monsoon system under different settings of climatological monsoonal circulation (Kosaka and Nakamura 2010; Li and Lu 2018). 
(a)

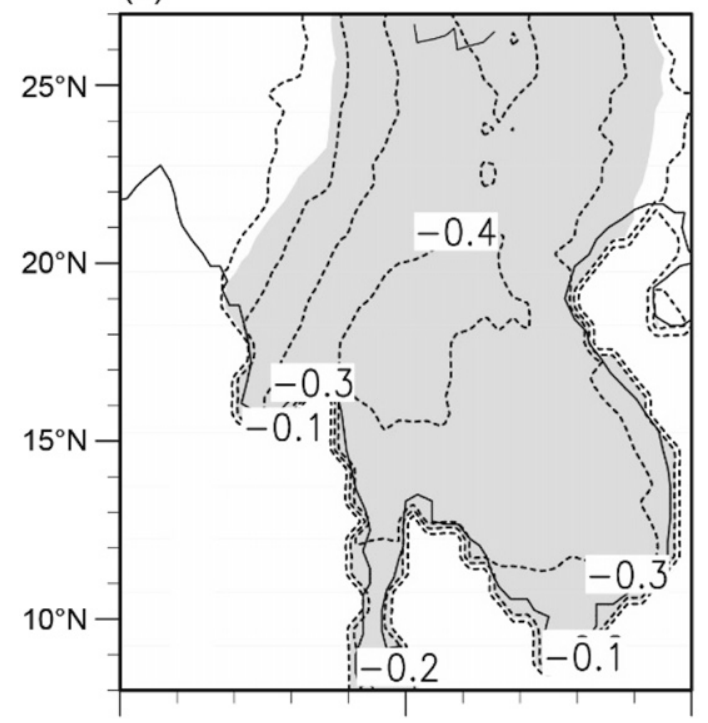

(c)

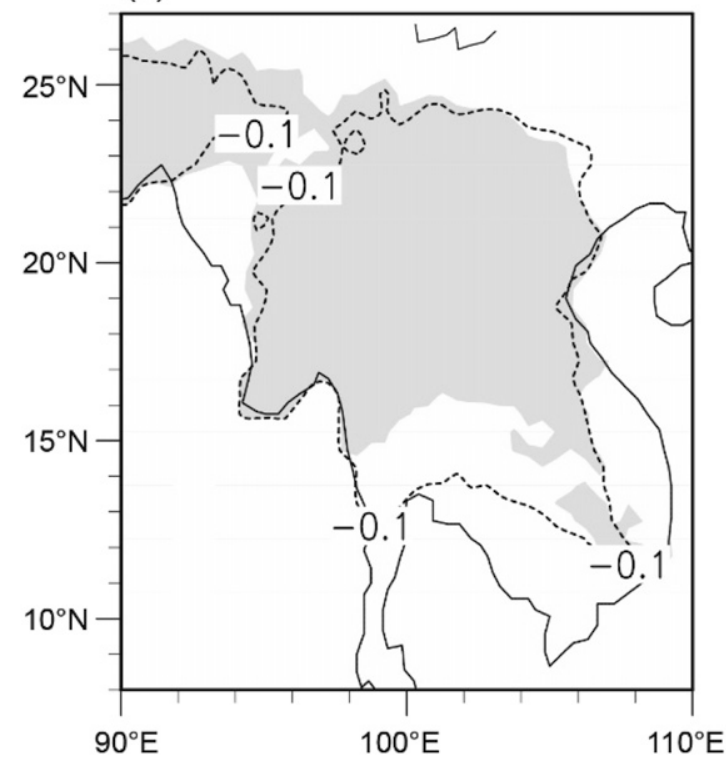

(b)

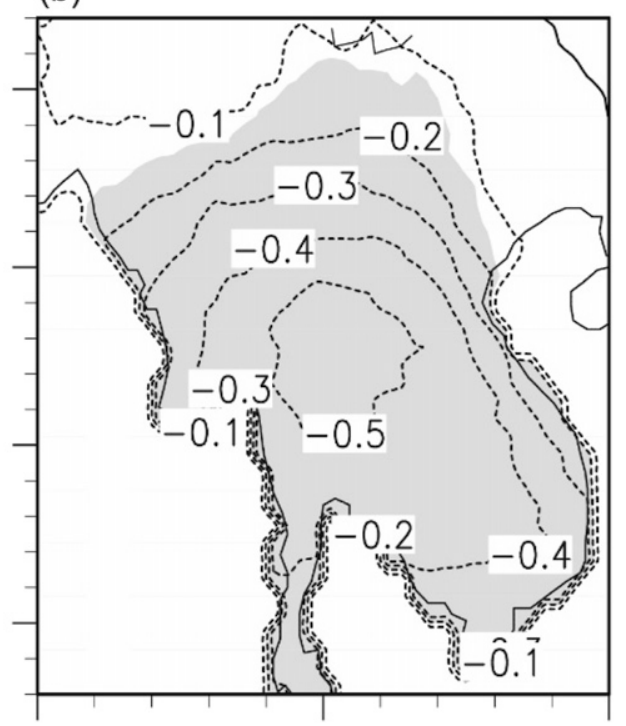

(d)

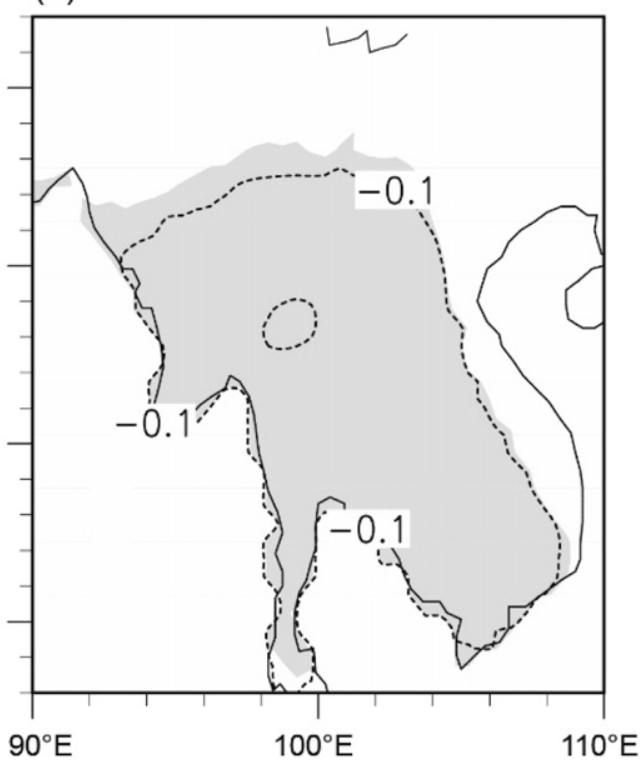

FIG. 6. Regression of (a) spring and (c) summer observed temperature anomalies (units: K) with respect to the standardized spring SM over the ICP for the period of 1961-91. (b),(d) As in (a) and (c), but for the period of 19922010. The shaded areas are significant with $p<0.1$. All data are linearly detrended.

\section{a. Interdecadal changes in the East Asian summer monsoon system}

To explore the changes in the monsoonal circulation, we first show the climatological summer precipitation, 700-hPa wind, and geopotential height fields in each period (Fig. 7). This pressure level is used to avoid the possible topographic influences of the mountains over southern China. As shown in Figs. $7 \mathrm{a}$ and $7 \mathrm{~b}$, the southwesterly wind prevails over southern China, which carries water vapor to feed the monsoonal precipitation. Thus, the precipitation decreases from south to north. Compared with the early period, the geopotential height is uplifted with a large value center in the South China Sea and a small one over the YRB in the late period (Fig. 7c). This leads to an enhanced southwesterly wind over southern China and a weakened southerly wind over the area north of the Yangtze River. The precipitation thus increases and decreases in southern and northern China, respectively. This is in agreement with 
(a) 1961-1991

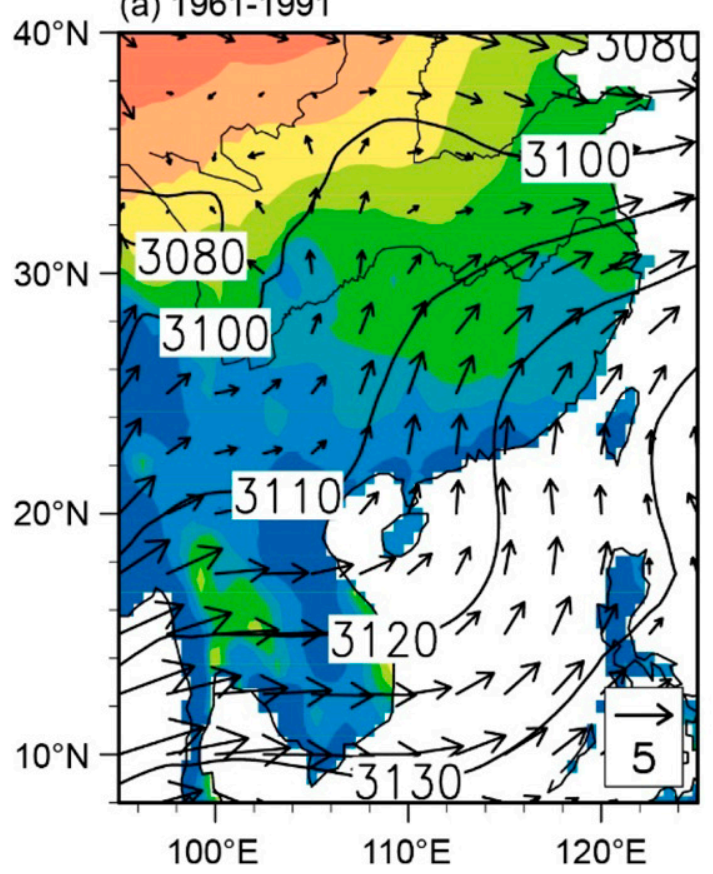

(b) $1992-2010$

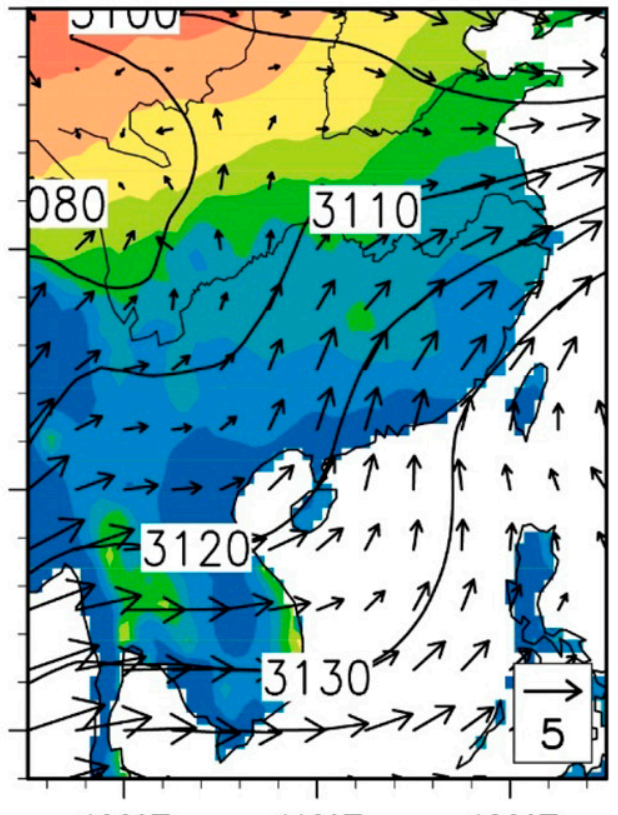

$100^{\circ} \mathrm{E} \quad 110^{\circ} \mathrm{E} \quad 120^{\circ} \mathrm{E}$

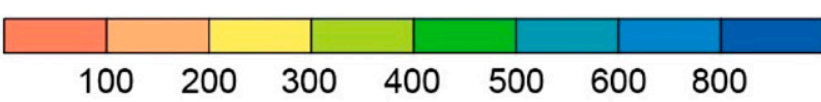

(c) Difference

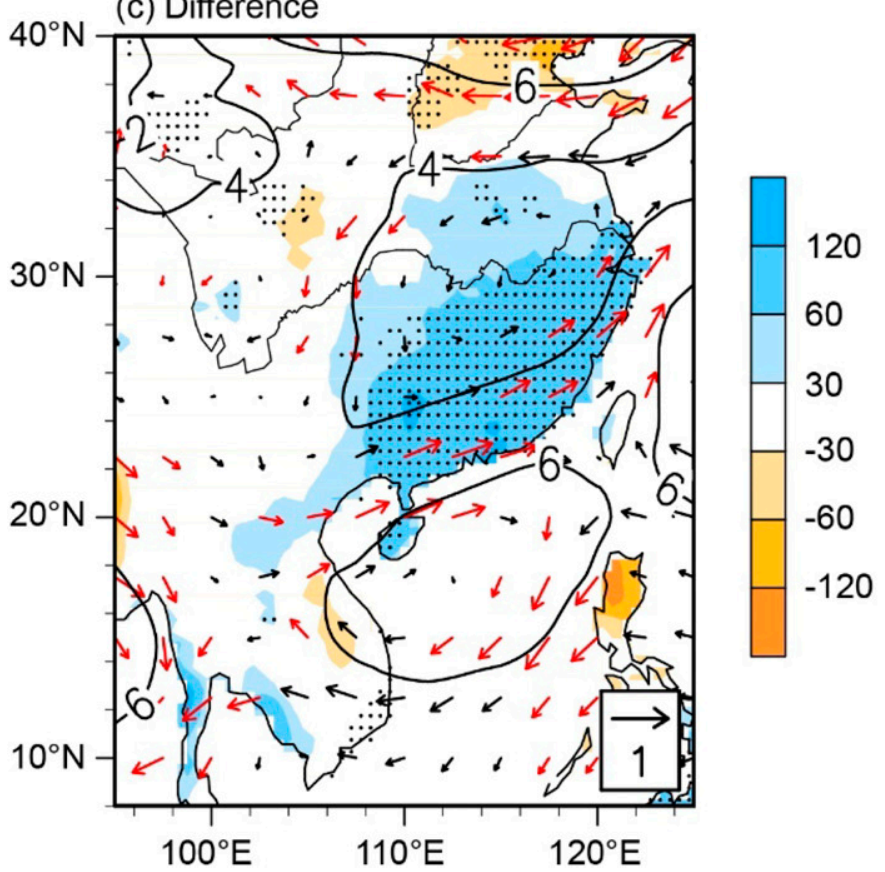

FIG. 7. Climatic states of precipitation (colors; units: mm), 700-hPa geopotential height (contours; units: gpm), and wind field (arrows; units: $\mathrm{m} \mathrm{s}^{-1}$ ) in summer during (a) 1961-91 and (b) 1992-2010. (c) Difference between the two periods $[(\mathrm{b})-(\mathrm{a})]$. The dots and red arrows are significant with $p<0.1$. 

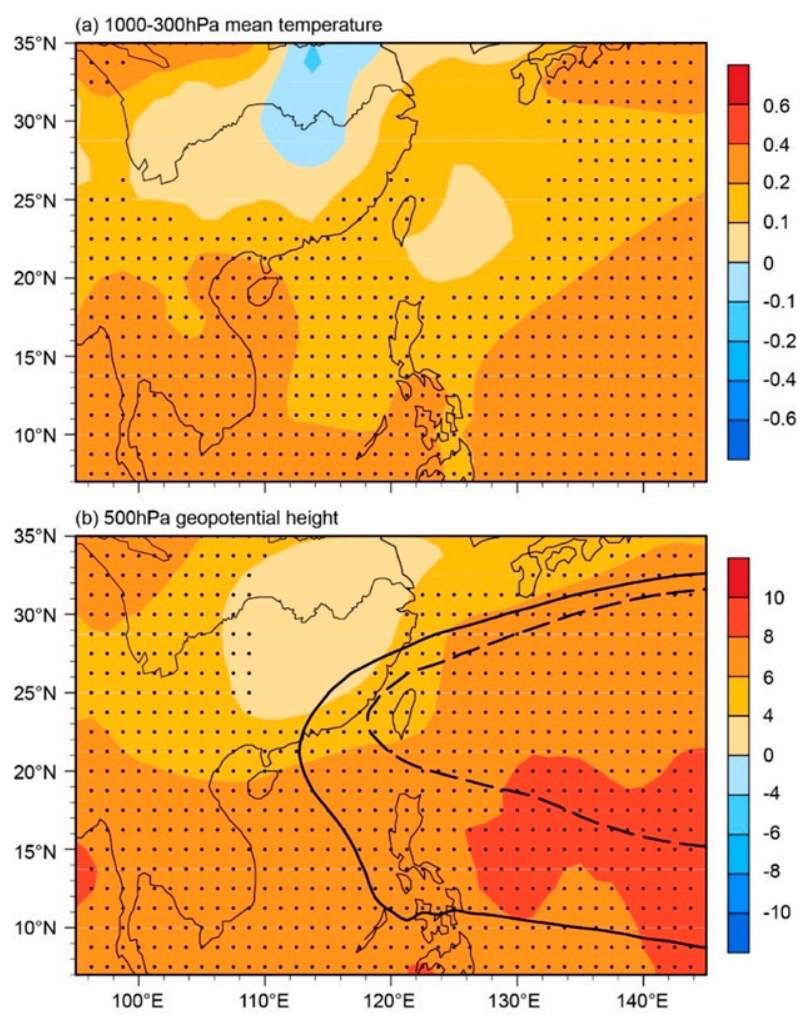

FIG. 8. (a) Difference of tropospheric temperature (averaged from 1000 to $300 \mathrm{hPa}$; units: K) in summer between two subperiods (climatic state of 1992-2010 minus that of 1961-91). The dots are significant with $p<0.1$. (b) As in (a), but for the 500-hPa geopotential height field (units: gpm). The dashed and solid lines in (b) denote the climatic main body of the western Pacific subtropical high (WPSH; $5860 \mathrm{gpm}$ ) during 1961-91 and 1992-2010, respectively.

previous studies (Ding et al. 2008, 2009) suggesting a weaker East Asian monsoon and a redistribution of summer precipitation since the early 1990s.

The WPSH is closely linked with the East Asian summer monsoon system and is changing with the climate shift (Gao et al. 2015). Basically, the summer tropospheric temperature increased during 1992-2010, especially the tropical area (Fig. 8a). The troposphere over the ICP and the western Pacific during the late period is evidently warmer than that of the early period by $0.1-0.4 \mathrm{~K}$ in summer. Meanwhile, the $500-\mathrm{hPa}$ geopotential height was uplifted over the tropical area (Fig. 8b). Here the climatic WPSH is marked by the averaged 5860-gpm contour in each subperiod. Indeed, with the warming over the tropical areas, the intensification and the westward extension of the WPSH are evident. This situation prevents the moisture from transporting northward, contributing to the redistribution of the climatic precipitation pattern over eastern China.
One of the major components of the summer monsoonal precipitation over the YRB is the mei-yu front rainfall (Ding and Chan 2005). For studying the mei-yu front, the equivalent potential temperature $\theta_{e}$ calculated by both temperature and humidity is a widely used variable (Chen and Zhai 2015; Park et al. 2015; Li and Lu 2017). A wetter and warmer air mass can be characterized by a higher $\theta_{e}$. A relatively larger meridional $\theta_{e}$ gradient in the lower troposphere over the YRB indicates the mei-yu front, and an anomalous meridional $\theta_{e}$ gradient indicates the variation of the mei-yu front intensity. Figure 9 illustrates the climatic $\theta_{e}$ and its meridional gradient $\left(-d \theta_{e} / d y\right)$, and the right panel shows the corresponding averaged $\theta_{e}$ gradient between $106^{\circ}$ and $116^{\circ} \mathrm{E}$. Generally, $\theta_{e}$ decreases from the south to the north with a large value center over southwestern China in each subperiod (Figs. 9a,b). This is due to the relatively colder and drier air in the north and the warmer and wetter air mass transported in the south. Thus, a mei-yu quasi-static front forms over the YRB in summer, causing the major climatological precipitation belt. As shown in the right panels of Figs. 9a and 9b, the climatological $\theta_{e}$ exhibits a sharp decrease with latitude across the YRB in summer. Compared to precipitation and atmospheric circulation, the climatic $\theta_{e}$ gradient between the two subperiods demonstrates relatively fewer differences: it increases in the south of the YRB and decreases over the southern China since 1990s (Fig. 3c). This indicates that the mei-yu front slightly moves southward, favoring more precipitation over the southern China in the late period.

\section{b. The monsoonal circulation and precipitation responses to $S M$ anomalies over the ICP}

The SM anomalies in spring over the ICP can persist until the following summer and induce the abnormal local surface temperature. The anomalous surface heating can regulate the local geopotential height (Fischer et al. 2007; Yang et al. 2019), which may influence the WPSH. However, the East Asian summer monsoon has experienced an interdecadal change, which might change the effect of SM on the large-scale circulation. In this section, we use the regression analysis to investigate the atmospheric responses to SM anomalies over the ICP.

During 1961-91, the tropospheric air temperature in summer over the ICP rises over $0.1 \mathrm{~K}$ when the spring SM anomaly occurs (here we take the SM anomaly of -1 standard deviation as an example) (Fig. 10a). Accordingly, the $500-\mathrm{hPa}$ geopotential height is also uplifted over the ICP by about 4 gpm (Fig. 10c). The abnormal geopotential height field forms an east-west zonal region. This situation indicates that the WPSH 

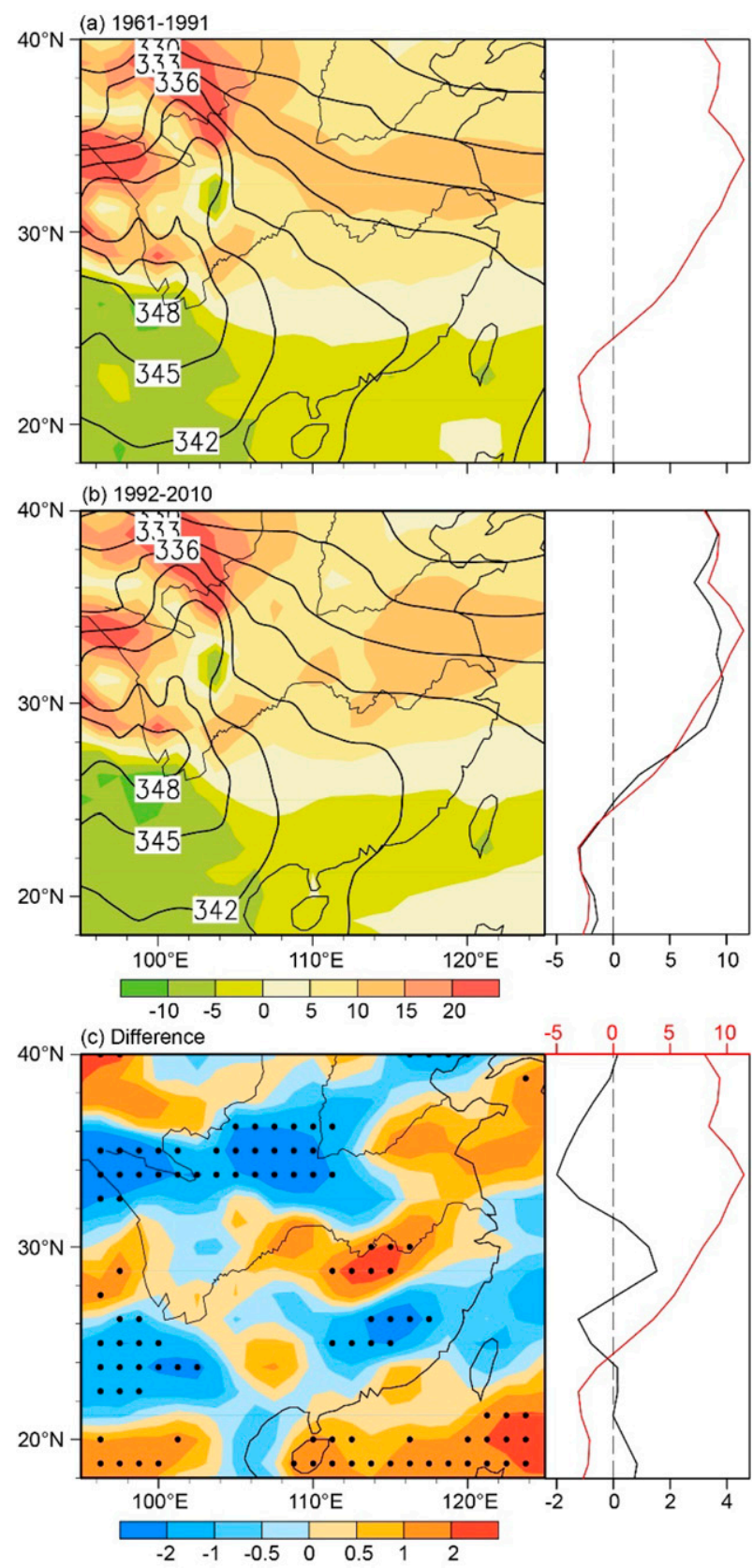

FIG. 9. (left) Climatic states of the 700-hPa summer equivalent potential temperature $\left(\theta_{e}\right.$; contours; units: K) during (a) 1961-91 and (b) 1992-2010, and the northward $\theta_{e}$ gradient $\left(-d \theta_{e} / d y\right.$; colors; units: $1 \times 10^{-6} \mathrm{~K} \mathrm{~m}^{-1}$ ). (c) Difference of $-d \theta_{e} / d y$ between the two periods [(b) - (a)]. The dots are significant with $p<0.1$. (right) The corresponding $-d \theta_{e} / d y$ averaged over $106^{\circ}-116^{\circ} \mathrm{E}$, with the red lines denoting the climatology of the $-d \theta_{e} / d y$ for the period of 1961-91.

is strengthened and extended westward when the ICP is abnormally drier. This would hinder the water vapor from transporting northward, benefiting precipitation over the YRB. In contrast, the tropospheric warming induced by the SM anomaly over the ICP is weaker (less than 0.1 K) during 1992-2010 (Fig. 10b). Correspondingly, the $500-\mathrm{hPa}$ geopotential height over the ICP is only uplifted by about $2 \mathrm{gpm}$, and its abnormal center is generally located over the western Pacific near the equator and extends northwestward to South China (Fig. 10d). The above findings primarily show different responses of the large-scale atmospheric circulation to the spring ICP SM anomaly reflected by the shapes of the abnormal WPSH in two subperiods.

Generally, the WPSH guides the low-level wind flow around its main body, and the abnormal WPSH would lead to an anomalous anticyclone wind field at the lower troposphere. Figure 11 further shows the responses of $700-\mathrm{hPa}$ wind and geopotential height in summer to the spring ICP SM anomalies. During 1961-91, the abnormal center of geopotential height with $5 \mathrm{gpm}$ distributes from southeastern China to the ICP zonally when spring SM is abnormally lower over the ICP (Fig. 11a). Accordingly, an anomalous anticyclone wind field is located along the western rim of the abnormal center, indicating a strengthened southwesterly wind over South China. Besides, an anomalous northerly wind in the north further prevents the water vapor transporting northward and favors precipitation over the YRB (Fig. 11a). This also indicates that the spring ICP SM anomaly induces the anomalous PacificJapan teleconnection pattern, which further influences summer precipitation over the YRB. During 1992-2010, the responses of the geopotential height and wind at $700 \mathrm{hPa}$ are much weaker (Fig. 11b). In summary, the responses of the southwesterly wind over the southern China exhibit a distinct difference between the two subperiods. This lower-troposphere wind plays a key role in guiding the air moisture transport, and is crucial to precipitation anomalies over the YRB.

The vertically integrated summer water vapor flux from 300 to $1000 \mathrm{hPa}$ is further calculated. Indeed, the responses of water vapor flux to the SM anomaly during two subperiods also exhibit an evident difference (Fig. 12). Over southern China, there is a stronger water vapor flux carrying air moisture northeastward to the YRB (Fig. 12a) during the early period, consistent with the 700-hPa anomalous wind field (Fig. 11a). It is accompanied by a northerly abnormal flux over the north, leading to an evident water vapor convergence over the YRB. In contrast, the response of water vapor flux is also insignificant over southern China during 1992-2010 (Fig. 12b).

To verify that the circulation anomaly plays the decisive role in the water vapor flux anomaly during each 


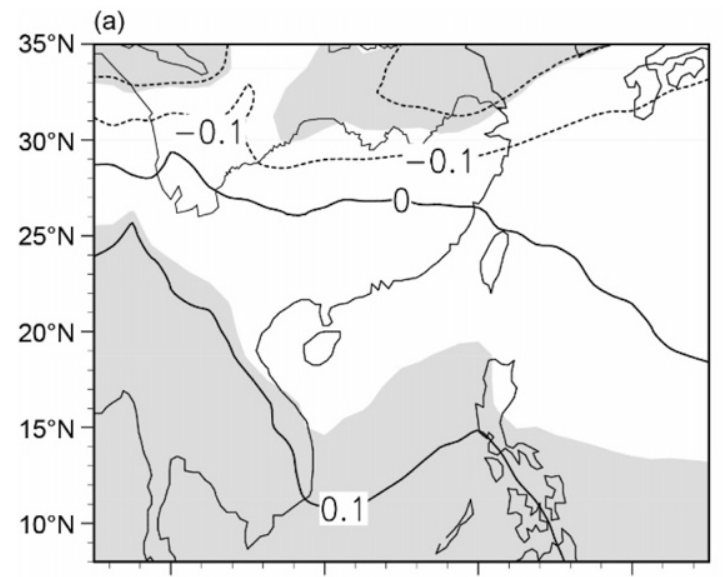

(b)
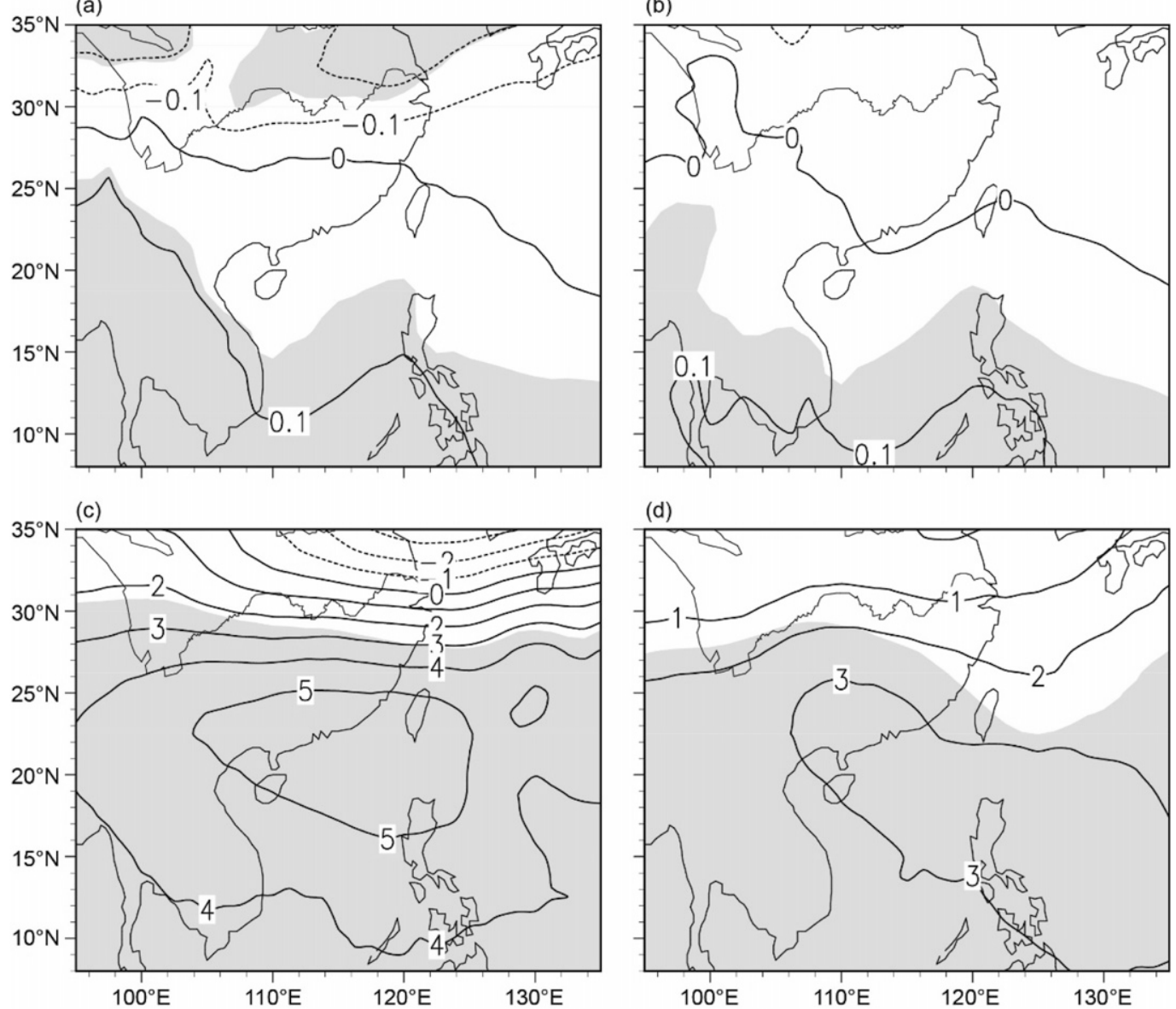

FIG. 10. Regression of summer (a) tropospheric air temperature (averaged from 1000 to $300 \mathrm{hPa}$; units: K) and (c) 500-hPa geopotential height (units: gpm) anomalies with respect to the negative standardized spring SM over the ICP for the period of 1961-91 (To make the corresponding SM anomaly favorable for precipitation over the YRB, the SM anomalies are multiplied by -1 ; hereafter the same). (b),(d) As in (a) and (c), but for the period of 1992-2010. The shaded areas are significant with $p<0.1$. All data are linearly detrended.

subperiod, the water vapor flux anomaly is divided into thermodynamic and dynamic processes as explained in section 2. These processes stand for the components of the flux anomaly related to the humidity and wind anomalies, respectively. Figure 13 shows the sum and the two components individually. The results in Figs. 13a and $13 \mathrm{~b}$ show high similarities with the response of total water vapor flux to the SM anomalies in Figs. 12a and $12 \mathrm{~b}$, which are in agreement with the description of Eq. (2) in section 2. Furthermore, the contributions of the dynamic process (Figs. 13e,f) are distinctly larger than those of the thermodynamic process (Figs. 13c,d) during two subperiods. Those results confirm that the response of water vapor flux to SM anomaly can be explained primarily by the responses of monsoonal circulation.

Given that the mei-yu front precipitation contributes the majority of the summer precipitation over the YRB, we further present the response of $\theta_{e}$ to SM anomalies in Fig. 14. During 1961-91, with more warm and moist air transported over southern China, the $\theta_{e}$ values are abnormally higher and lower to the south and north of the Yangtze River, respectively (Fig. 14a). This leads to an abnormally larger $\theta_{e}$ gradient across the YRB, which is beneficial to enhance the mei-yu front and thus to increase the precipitation over the YRB. In contrast, during 1992-2010, the responses of monsoonal circulation to SM anomalies are much weaker. The mei-yu front exhibits less change, reflected by the smaller $\theta_{e}$ gradient anomalies over the YRB (Fig. 14b).

Figure 15 shows the relationships among the spring $\mathrm{SM}$, the mei-yu front intensity, and the summer YRB precipitation anomalies, which can help us to better understand the weakening influence of the spring ICP SM on the summer YRB precipitation. First, the 
(a) 1961-1991

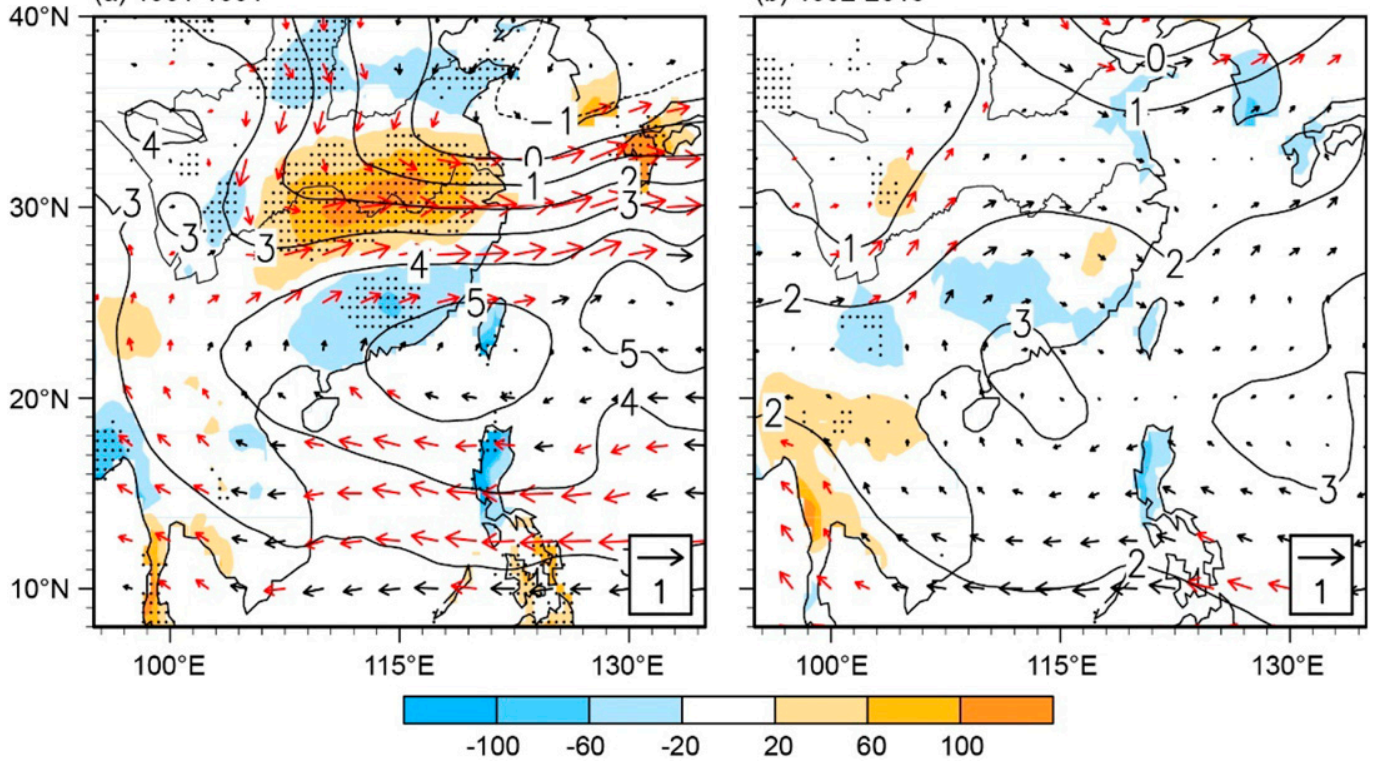

FIG. 11. Regression of summer precipitation (colors; units: $\mathrm{mm}$ ), 700-hPa geopotential height (contours; units: $\mathrm{gpm}$ ), and wind (arrows; units: $\mathrm{m} \mathrm{s}^{-1}$ ) anomalies with respect to the negative standardized spring SM over the ICP for the periods (a) 1961-91 and (b) 1992-2010. The dots and red arrows are significant with $p<0.1$. All data are linearly detrended. summer precipitation over the YRB is strongly associated with the mei-yu front. Thus, during the two subperiods, the mei-yu front intensity is evidently correlated with the YRB precipitation in summer, with correlation coefficients equal to 0.73 and 0.41 (Figs. 15a,b), which are both statistically significant. For the period of 1961-91, due to its strong effect on the local thermal states and thus monsoonal circulation, (a) $1961-1991$

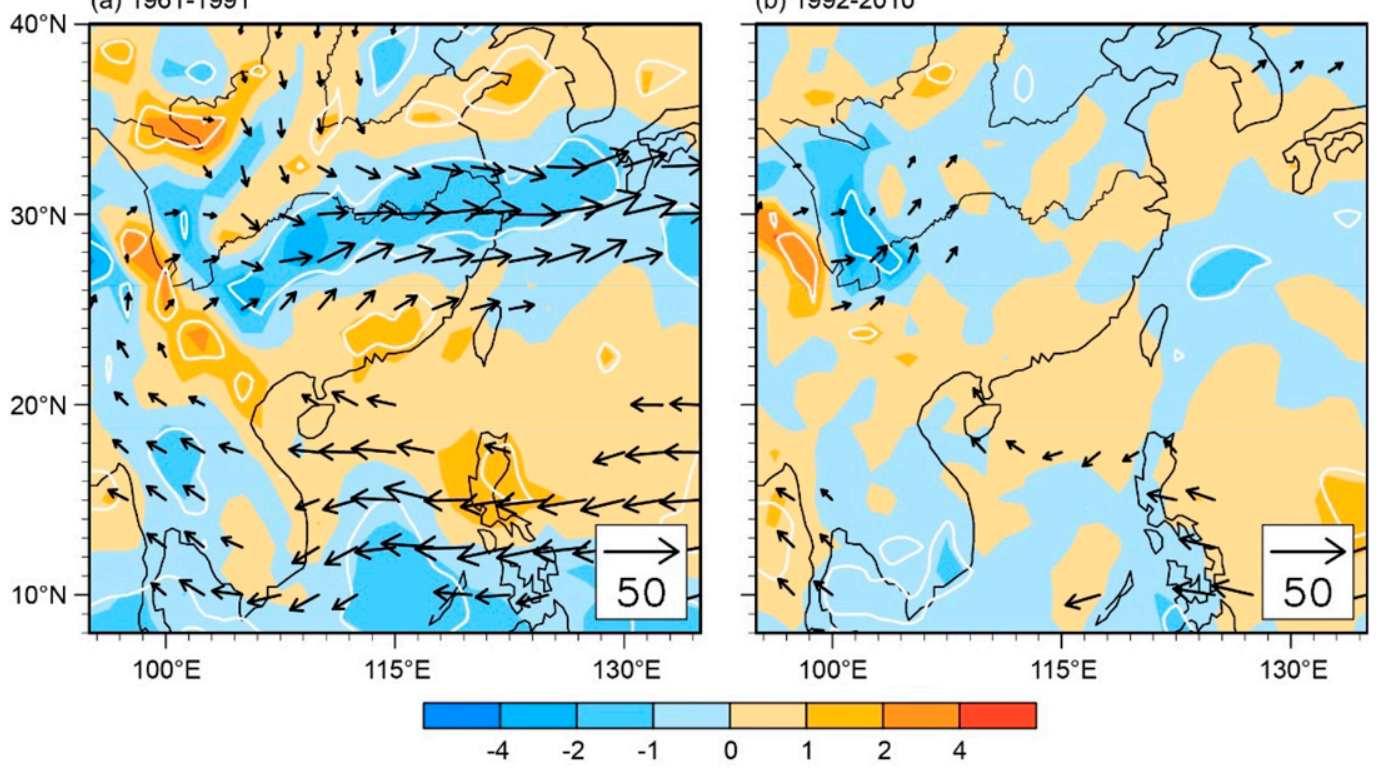

FIG. 12. Regression of summer water vapor flux (arrows; units: $\mathrm{kg} \mathrm{m}^{-1} \mathrm{~s}^{-1}$ ) and its divergence (colors; units: $1 \times$ $10^{5} \mathrm{~kg} \mathrm{~m}^{-2} \mathrm{~s}^{-1}$ ) anomalies integrated from 300 to $1000 \mathrm{hPa}$ with respect to the negative standardized spring SM over the ICP for the periods (a) 1961-91 and (b) 1992-2010. The arrows and the areas within white lines are significant with $p<0.1$. All data are linearly detrended. 
(a) $1961-1991$

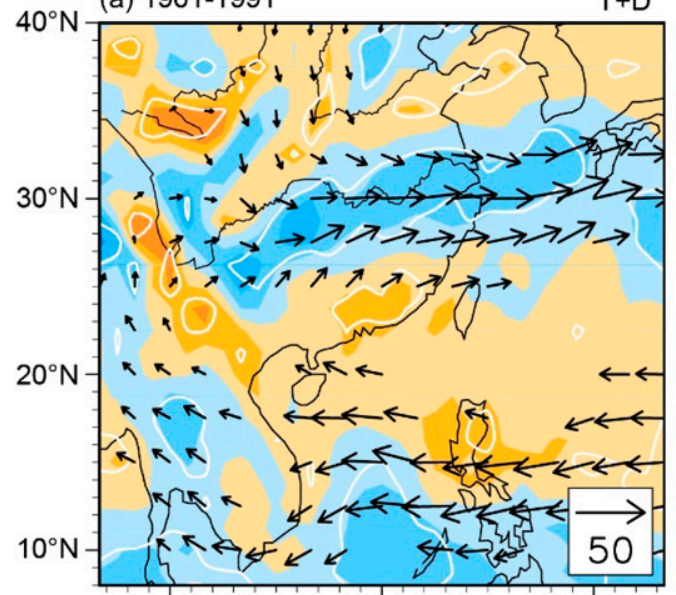

(c) 1961-1991

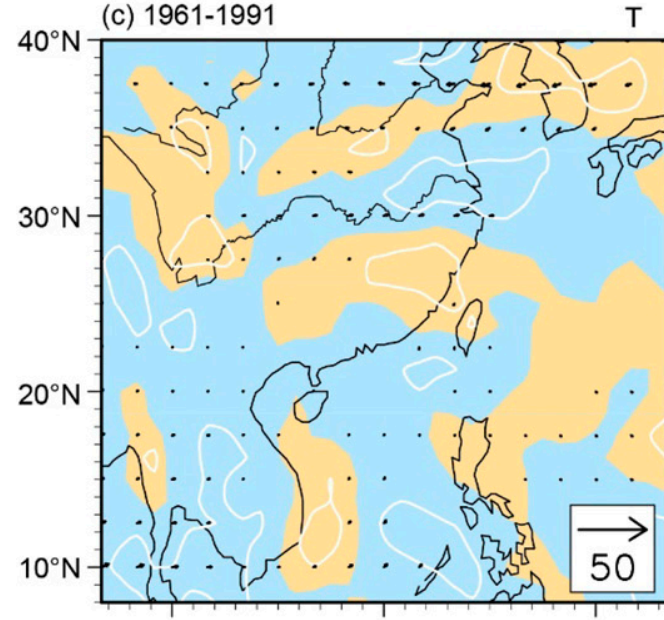

(b) $1992-2010$

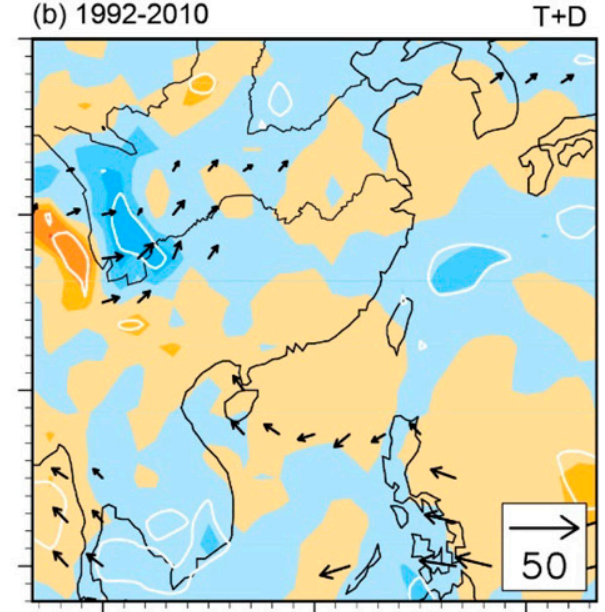

(d) $1992-2010$

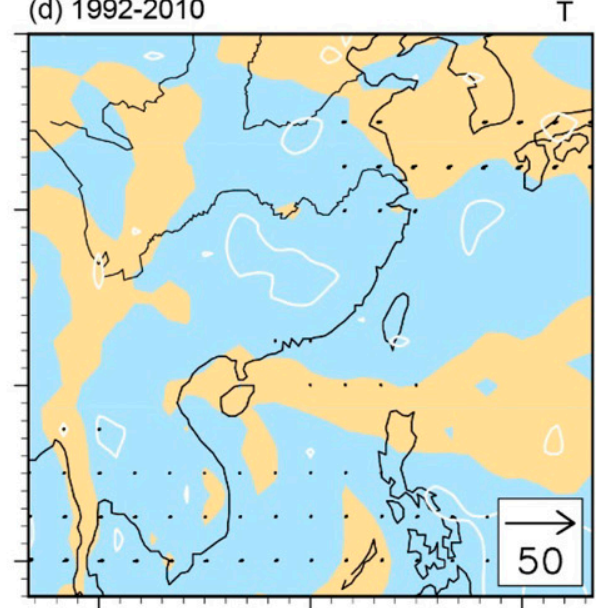

(f) $1992-2010$

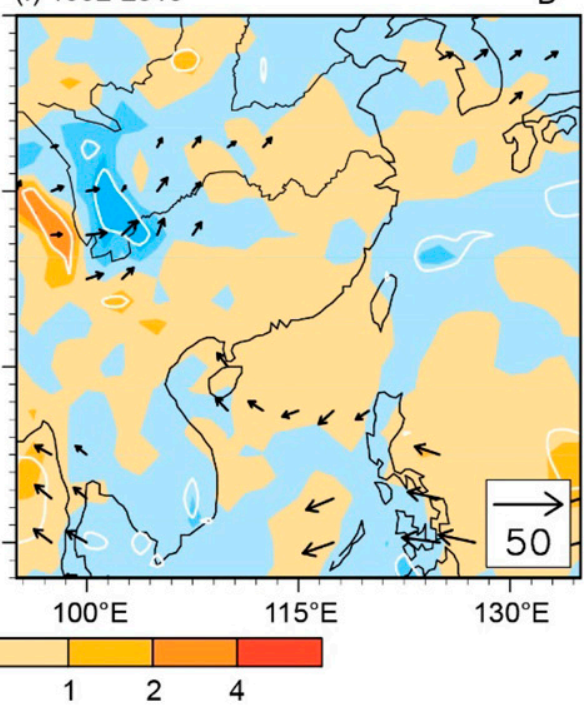

FIG. 13. As in Fig. 12, but for (a),(b) the sum of thermodynamic and dynamic components $(T+D)$, (c),(d) the thermodynamic component $(T)$, and (e),(f) the dynamic component $(D)$. 
(a) $1961-1991$

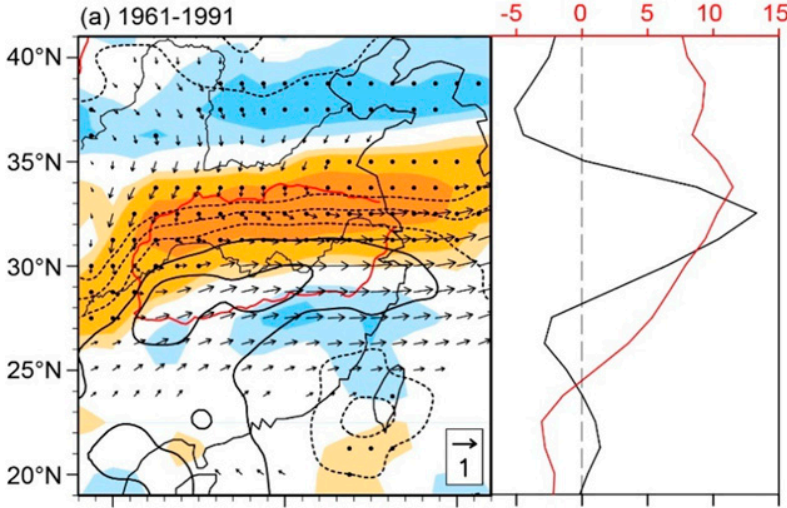

(b) $1992-2010$

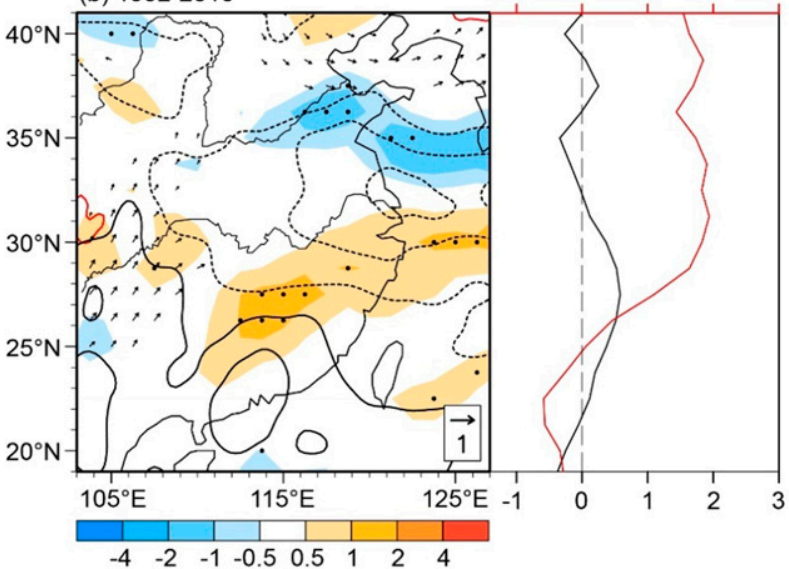

FIG. 14. (left) Regression of the 700-hPa summer equivalent potential temperature $\left(\theta_{e}\right.$; contours; units: $\left.\mathrm{K}\right)$, wind (arrows; units: $\mathrm{m} \mathrm{s}^{-1}$ ), and northward $\theta_{e}$ gradient $\left(-d \theta_{e} / d y\right.$; colors; units: $\left.1 \times 10^{-6} \mathrm{~K} \mathrm{~m}^{-1}\right)$ anomalies with respect to the negative standardized spring SM over the ICP for the periods of (a) 1961-91 and (b) 1992-2010. The dashed and continuous lines denote the negative and positive values of $\theta_{e}$ anomaly, respectively. The contour interval is $0.2 \mathrm{~K}$, and the zero contours are not shown. The colored areas with dots are significant with $p<0.1$. The areas within the red lines in which the precipitation anomalies are significant with $p<0.1$, and only the wind anomalies significant with $p<0.1$ are shown for comparison. (right) The corresponding $-d \theta_{e} / d y$ anomalies (black lines) averaged over $106^{\circ}-116^{\circ} \mathrm{E}$, with the red lines denoting the climatic states of the $-d \theta_{e} / d y$ for the two periods. All data are linearly detrended.

the ICP SM has a robust negative relationship with the mei-yu front intensity (Fig. 15c). Specifically, a drier surface over the ICP increases the local temperature and geopotential height (Figs. 6 and 10), benefitting westward extension of the WPSH. The resultant excessive moisture transporting to the YRB accompanied by a stronger southwesterly monsoonal wind further enhances the mei-yu front (Figs. 11a, 12a, and 14a). As a result, there is a strong relationship between the spring ICP SM and the summer YRB precipitation, reflected by a significant $(p<0.001)$ negative correlation coefficient of -0.69 (Fig. 15e). On the other hand, with evident climate shift of the East Asian monsoon system (Figs. 7-9) during the late period (1992-2010), the linkage in the mei-yu front intensity and the YRB precipitation is still evident (Fig. 15b); the effect of the ICP SM anomaly on the mei-yu front intensity, however, is dramatically weakened with a correlation coefficient of -0.01 (Fig. 15d). This is due to the weakening responses of local tropospheric air temperature and geopotential height to abnormal surface heating induced by spring SM anomaly over the ICP (Figs. 10b,d), which leads to little change of the monsoonal circulations (Figs. 11b, 12b). Finally, the relationship between the spring ICP SM and the summer YRB precipitation anomalies almost vanishes during 1992-2010 (Fig. 15f).

\section{Conclusions and discussion}

Due to its persistent ability, SM is a reliable seasonal predictor (Gao et al. 2017). In this work, a significantly negative correlation is found between the spring SM over the ICP and the summer precipitation over the YRB for the period of 1961-2010. However, this relationship exhibits a large interdecadal instability with a much weaker correlation in the recent decade (1992-2010) than in the period before 1992 (1961-91).

Generally speaking, in spring, the ICP exhibits a strong land-atmosphere coupling: an abnormally drier soil constrains the surface evapotranspiration and raises the local air temperature, and vice versa. Moreover, such an effect of SM regulating the local surface thermal condition can last from spring to summer. Theoretically, the abnormal surface heating (cooling) over the ICP could lead to an increase (decrease) in local geopotential height. This potentially affects the zonal shift of the WPSH and thus the East Asian summer monsoon system.

Before the early 1990s, for example, the geopotential height in summer over the ICP increases, associated with the abnormal local heating induced by drier soil in spring. This leads to a westward extension of the WPSH, resulting in a strengthened southwesterly wind over southern China and an excessive moisture transported to the YRB. With wetter and warmer air in the south, the meridional $\theta_{e}$ gradient increases over the YRB, which reflects an intensification of the mei-yu front. Therefore, the summer monsoonal precipitation abnormally increases over the YRB.

Since the early 1990s, the East Asian summer monsoon has experienced an abrupt interdecadal shift, with an excessive westward extension of the WPSH and the rain belt moving southward. The effects of the abnormal surface heating over the ICP induced by the 
(a)

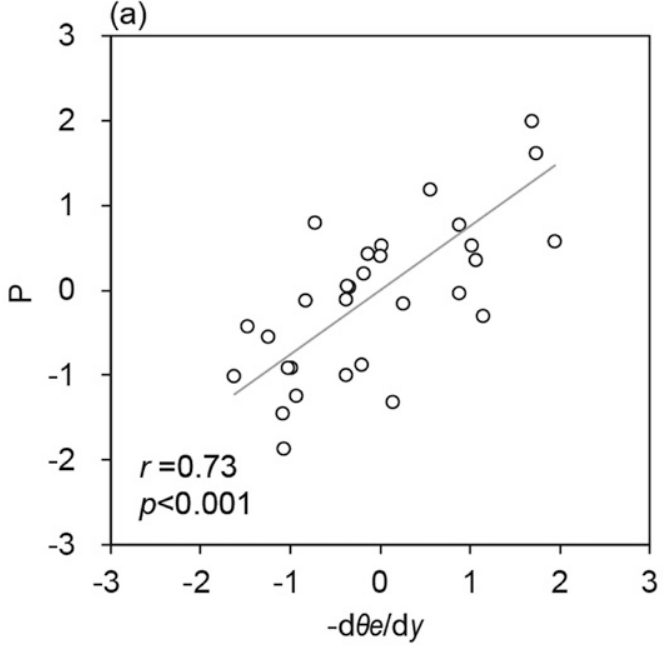

(c)

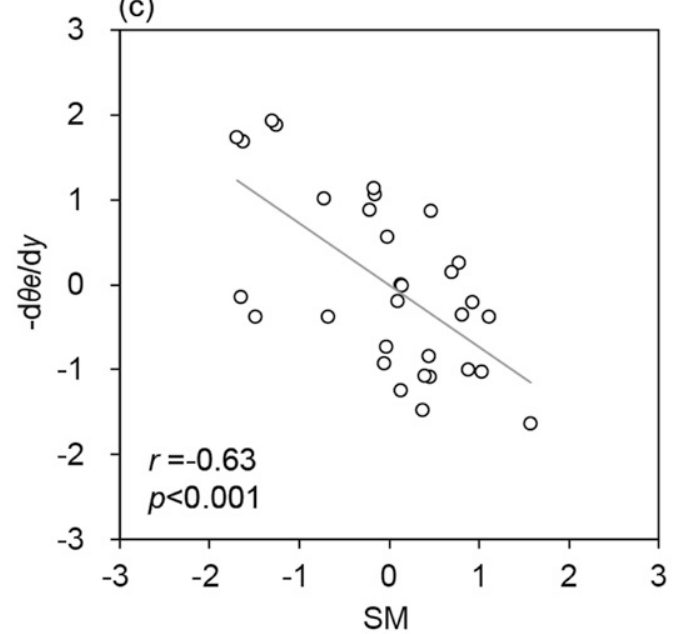

(e)

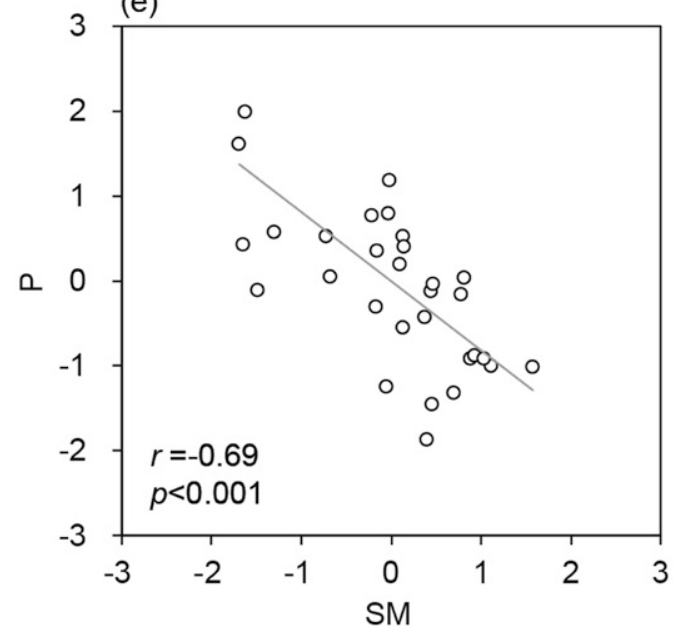

(b)

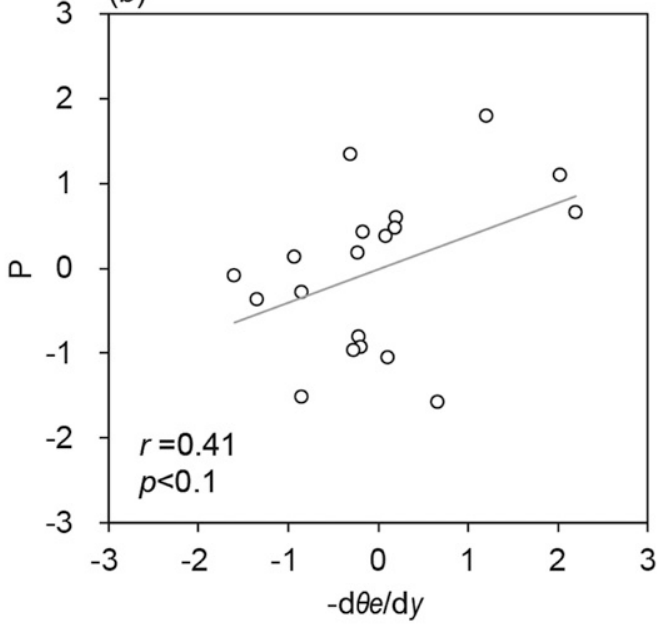

(d)

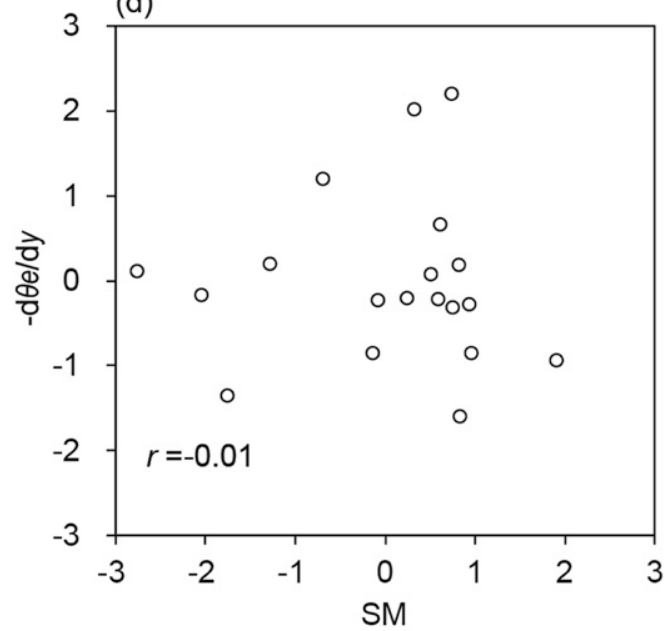

(f)

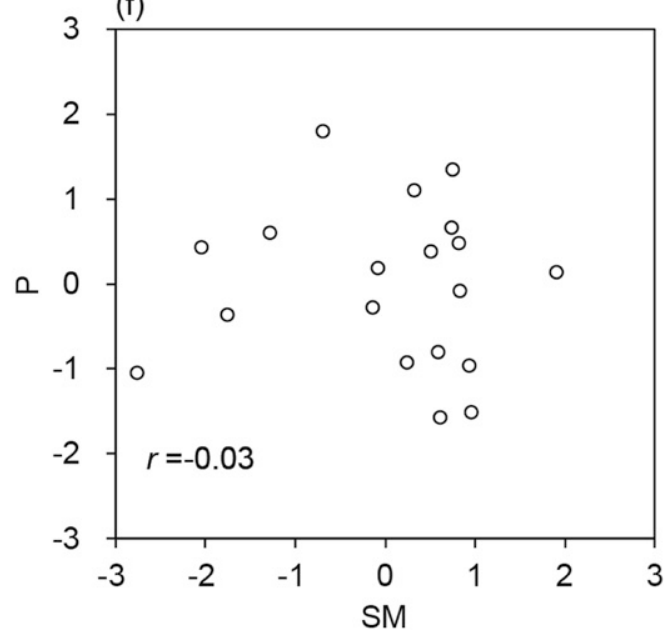

FIG. 15. Relationships (a) between the summer $-d \theta_{e} / d y$ and precipitation $(P)$ over the YRB, (c) between spring soil moisture (SM) over the ICP and summer $-d \theta_{e} / d y$ over the YRB, and (e) between spring SM over the ICP and summer $P$ over the YRB for 1961-91. (b),(d),(f) As in (a), (c), and (e), but for 1992-2010. All data are linearly detrended and standardized. 
SM anomaly on the atmosphere would vary with those changing climatic backgrounds. In our study, the results suggest that such effects are diminished. Particularly, the responses of summer tropospheric air temperature and geopotential height over the ICP to local SM anomaly are weakened during 1992-2010. Correspondingly, the southwesterly wind anomaly over southern China associated with the ICP SM anomaly has weakened, which could lead to a weakened anomaly of water vapor advection to the YRB. Hence, the resulting abnormal meiyu front intensity associated with monsoonal circulation anomalies is also weakened, leading to a smaller summer precipitation anomaly over the YRB compared to the early period. As a result, the influence of spring SM over the ICP on the precipitation over the YRB has largely weakened since the early 1990s.

Our findings highlight the importance of spring SM over the ICP for predicting the East Asian summer monsoon and the summer precipitation over the YRB. But the present study also finds that this effect is experiencing an interdecadal weakening against the background of climate change since the early 1990s, accompanied by abrupt shifts of the climatological East Asian summer monsoon system and the WPSH. Our analyses also imply that the spring SM anomaly over the ICP is mainly induced by abnormal local precipitation, which may be closely related to the abnormal atmospheric circulation associated with the SSTA. This could be further explored in the future.

Acknowledgments. This work was supported by the Fundamental Research Funds for the Central Universities (2018B03114 and 2019B18814), the Natural Science Foundation of China (41831175, 41905054, and 41861144013), the China Postdoctoral Science Foundation (2019M651665), the Open Research Fund of the State Key Laboratory of Loess and Quaternary Geology of China (SKLLQG1806), and the Joint Open Project of Key Laboratory of Meteorological Disaster, Ministry of Education/Collaborative Innovation Center on Forecast and Evaluation of Meteorological Disasters, Nanjing University of Information Science and Technology (KLME202006).

\section{REFERENCES}

Bellucci, A., and Coauthors, 2015: Advancements in decadal climate predictability: The role of nonoceanic drivers. Rev. Geophys., 53, 165-202, https://doi.org/10.1002/2014RG000473.

Chen, J., and L. Chen, 1991: Influence of ocean-continent distribution in the south part of Asia on the formation of Asian summer monsoon (in Chinese). J. Appl. Meteor. Sci., 2, 355-361.

Chen, Y., and P. Zhai, 2015: Synoptic-scale precursors of the East Asia/Pacific teleconnection pattern responsible for persistent extreme precipitation in the Yangtze River Valley. Quart. J. Roy. Meteor. Soc., 141, 1389-1403, https://doi.org/10.1002/ qj.2448.

Cheng, S. J., and J. P. Huang, 2016: Enhanced soil moisture drying in transitional regions under a warming climate. J. Geophys. Res. Atmos., 121, 2542-2555, https://doi.org/ 10.1002/2015JD024559.

- X. D. Guan, J. P. Huang, F. Ji, and R. X. Guo, 2015: Longterm trend and variability of soil moisture over East Asia. J. Geophys. Res. Atmos., 120, 8658-8670, https://doi.org/ 10.1002/2015JD023206.

Ding, Y., and J. C. L. Chan, 2005: The East Asian summer monsoon: An overview. Meteor. Atmos. Phys., 89, 117-142, https:// doi.org/10.1007/s00703-005-0125-z.

, Z. Wang, and Y. Sun, 2008: Inter-decadal variation of the summer precipitation in East China and its association with decreasing Asian summer monsoon. Part I: Observed evidences. Int. J. Climatol., 28, 1139-1161, https://doi.org/10.1002/ joc.1615.

, Y. Sun, Z. Wang, Y. Zhu, and Y. Song, 2009: Inter-decadal variation of the summer precipitation in China and its association with decreasing Asian summer monsoon. Part II: Possible causes. Int. J. Climatol., 29, 1926-1944, https://doi.org/ 10.1002/joc.1759.

Dirmeyer, P. A., 2011: The terrestrial segment of soil moistureclimate coupling. Geophys. Res. Lett., 38, L16702, https:// doi.org/10.1029/2011GL048268.

- C. C. A. Schlosser, and K. L. Brubaker, 2009: Precipitation, recycling, and land memory: An integrated analysis. J. Hydrometeor., 10, 278-288, https://doi.org/10.1175/ 2008JHM1016.1.

Douville, H., 2002: Influence of soil moisture on the Asian and African monsoons. Part II: Interannual variability. J. Climate, 15, 701-720, https://doi.org/10.1175/1520-0442(2002)015<0701: IOSMOT $>2.0 . \mathrm{CO} ; 2$

- - F. Chauvin, and H. Broqua, 2001: Influence of soil moisture on the Asian and African monsoons. Part I: Mean monsoon and daily precipitation. J. Climate, 14, 23812403, https://doi.org/10.1175/1520-0442(2001)014<2381: IOSMOT $>2.0 . \mathrm{CO} ; 2$.

Fischer, E. M., S. I. Seneviratne, P. L. Vidale, D. Lüthi, and C. Schär, 2007: Soil moisture-atmosphere interactions during the 2003 European summer heat wave. J. Climate, 20, 50815099, https://doi.org/10.1175/JCLI4288.1.

Gao, C., H. Chen, S. Sun, V. Ongoma, W. Hua, H. Ma, B. Xu, and Y. Li, 2017: A potential predictor of multi-season droughts in Southwest China: Soil moisture and its memory. Nat. Hazards, 91, 553-566, https://doi.org/10.1007/s11069-017-3140-8.

, and Coauthors, 2019: Land-atmosphere interaction over the Indo-China Peninsula during spring and its effect on the following summer climate over the Yangtze River basin. Climate Dyn., 53, 6181-6198, https://doi.org/10.1007/s00382019-04922-x.

Gao, H., W. Jiang, and W. Li, 2015: Changed relationships between the East Asian summer monsoon circulations and the summer rainfall in eastern China. J. Meteor. Res., 28, 1075-1084, https://doi.org/10.1007/s13351-014-4327-5.

He, J., Z. Bing, W. Min, and L. Feng, 2001: Vertical circulation structure, interannual variation features and variation mechanism of western Pacific subtropical high. Adv. Atmos. Sci., 18, 497-510, https://doi.org/10.1007/s00376-001-0040-2.

Huang, R., Y. Xu, P. Wang, and L. Zhou, 1998: The features of the catastrophic flood over the Changjiang river basin during the 
summer of 1998 and cause exploration (in Chinese). Climatic Environ. Res., 3, 300-313.

Jiang, T., Z. W. Kundzewicz, and B. Su, 2010: Changes in monthly precipitation and flood hazard in the Yangtze River Basin, China. Int. J. Climatol., 28, 1471-1481, https://doi.org/10.1002/ joc. 1635 .

Jin, Q., J. He, L. Chen, and C. Zhu, 2006: Impacts of ocean-land distribution over the southern Asia and the continents over the Southern Hemisphere on the formation of Asian summer monsoon circulation (in Chinese). Chin. J. Atmos. Sci., 30, 1043-1053.

Kobayashi, S., and Coauthors, 2015: The JRA-55 reanalysis: General specifications and basic characteristics. J. Meteor. Soc. Japan Ser. II, 93, 5-48, https://doi.org/10.2151/JMSJ.2015-001.

Kosaka, Y., and H. Nakamura, 2010: Mechanisms of meridional teleconnection observed between a summer monsoon system and a subtropical anticyclone. Part I: The Pacific-Japan pattern. J. Climate, 23, 5085-5108, https://doi.org/10.1175/ 2010JCLI3413.1.

Koster, R. D., and M. J. Suarez, 2001: Soil moisture memory on climate models. J. Hydrometeor., 2, 558-570, https://doi.org/ 10.1175/1525-7541(2001)002<0558:SMMICM > 2.0.CO;2.

Li, X., and R. Lu, 2017: Extratropical factors affecting the variability in summer precipitation over the Yangtze River basin, China. J. Climate, 30, 8357-8374, https://doi.org/10.1175/JCLID-16-0282.1.

_ and - 2018: Subseasonal change in the seesaw pattern of precipitation between the Yangtze River basin and the tropical western North Pacific during summer. Adv. Atmos. Sci., 35, 1231-1242, https://doi.org/10.1007/s00376-018-7304-6.

Liang, L., and H. Chen, 2010: Possible linkage between spring soil moisture anomalies over South China and summer rainfall in China (in Chinese). Trans. Atmos. Sci., 33, 536-546.

Liu, L., R. Zhang, and Z. Zuo, 2017: Effect of spring precipitation on summer precipitation in eastern China: Role of soil moisture. J. Climate, 30, 9183-9194, https://doi.org/10.1175/JCLI-D-17-0028.1.

Ma, J., S. Yang, and Z. Wang, 2018: Influence of spring soil moisture anomaly in the Indo-China peninsula on the establishment and development of Asian tropical summer monsoon (in Chinese). Meteor. Environ. Sci., 41, 19-30.

Meng, L., D. Long, S. M. Quiring, and Y. Shen, 2014: Statistical analysis of the relationship between spring soil moisture and summer precipitation in East China. Int. J. Climatol., 34, 15111523, https://doi.org/10.1002/joc.3780.

Park, H. S., B. R. Lintner, W. R. Boos, and K. H. Seo, 2015: The effect of midlatitude transient eddies on monsoonal southerlies over eastern China. J. Climate, 28, 8450-8465, https:// doi.org/10.1175/JCLI-D-15-0133.1.

Piao, S., L. Yin, X. Wang, P. Ciais, S. Peng, Z. Shen, and S. I. Seneviratne, 2009: Summer soil moisture regulated by precipitation frequency in China. Environ. Res. Lett., 4, 044012, https://doi.org/10.1088/1748-9326/4/4/044012.

Rayner, N., D. E. Parker, E. Horton, C. K. Folland, L. V. Alexander, D. Rowell, E. Kent, and A. Kaplan, 2003: Global analyses of sea surface temperature, sea ice, and night marine air temperature since the late nineteenth century. J. Geophys. Res., 108, D144407, https://doi.org/10.1029/2002JD002670.

Rodell, M., and Coauthors, 2004: The Global Land Data Assimilation System. Bull. Amer. Meteor. Soc., 85, 381-394, https://doi.org/ 10.1175/BAMS-85-3-381.

Seager, R., N. Naik, and G. A. Vecchi, 2010: Thermodynamic and dynamic mechanisms for large-scale changes in the hydrological cycle in response to global warming. J. Climate, $\mathbf{2 3}, 4651-4668$, https://doi.org/10.1175/2010JCLI3655.1.

Seneviratne, S. I., T. Corti, E. L. Davin, M. Hirschi, E. B. Jaeger, I. Lehner, B. Orlowsky, and A. J. Teuling, 2010: Investigating soil moisture-climate interactions in a changing climate: A review. Earth-Sci. Rev., 99, 125-161, https://doi.org/10.1016/ j.earscirev.2010.02.004.

Wang, H., and H. Chen, 2012: Climate control for southeastern China moisture and precipitation: Indian or East Asian monsoon? J. Geophys. Res., 117, D12109, https://doi.org/ 10.1029/2012JD017734.

Wang, S., and Y. Qian, 2001: Basic characteristic of surface heat field in 1998 and the possible connections with the SCS summer monsoon onset (in Chinese). Acta Meteor. Sin., 59, 31-40.

Wei, J., P. A. Dirmeyer, M. G. Bosilovich, and R. Wu, 2012: Water vapor sources for Yangtze River Valley rainfall: Climatology, variability, and implications for rainfall forecasting. J. Geophys. Res., 117, D05126, https://doi.org/10.1029/2011JD016902.

Wu, L., and J. Zhang, 2013: Asymmetric effects of soil moisture on mean daily maximum and minimum temperatures over eastern China. Meteor. Atmos. Phys., 122, 199-213, https://doi.org/ 10.1007/s00703-013-0284-2.

Xie, S.-P., Y. Kosaka, Y. Du, K. Hu, J. S. Chowdary, and G. Huang, 2016: Indo-western Pacific Ocean capacitor and coherent climate anomalies in post-ENSO summer: A review. Adv. Atmos. Sci., 33, 411-432, https://doi.org/10.1007/s00376-015-5192-6.

Yang, K., J. Zhang, L. Wu, and J. Wei, 2019: Prediction of summer hot extremes over the middle and lower reaches of the Yangtze River valley. Climate Dyn., 52, 2943-2957, https:// doi.org/10.1007/s00382-018-4302-4.

Zhan, Y., and Z. Lin, 2011: The relationship between June precipitation over mid-lower reaches of the Yangtze River basin and spring soil moisture over the East Asian monsoon region. Acta Meteor. Sin., 25, 355-363, https://doi.org/10.1007/s13351011-0310-6.

Zhang, L., and T. Zhou, 2015: Drought over East Asia: A review. J. Climate, 28, 3375-3399, https://doi.org/10.1175/JCLI-D-1400259.1 .

Zhang, R., and Z. Zuo, 2011: Impact of spring soil moisture on surface energy balance and summer monsoon circulation over East Asia and precipitation in East China. J. Climate, 24, 33093322, https://doi.org/10.1175/2011JCLI4084.1.

Zhang, W. J., and Coauthors, 2016: Unraveling El Niño's impact on the East Asian monsoon and Yangtze River summer flooding. Geophys. Res. Lett., 43, 11 375-11382, https://doi.org/10.1002/ 2016GL071190.

Zhang, Y., and Y. Qian, 2002: Mechanism of thermal features over the Indo-China Peninsula and possible effects on the onset of the South China Sea monsoon. Adv. Atmos. Sci., 19, 885-900, https://doi.org/10.1007/s00376-002-0053-5.

Zittis, G., P. Hadjinicolaou, and J. Lelieveld, 2013: Land-atmosphere coupling: The feedback of soil moisture in to surface temperature in eastern Mediterranean and Middle East. Advances in Meteorology, Climatology and Atmospheric Physics, C. Helmis and P. Nastos, Eds., Springer, 833-839.

Zuo, Z., and R. Zhang, 2007: The spring soil moisture and the summer rainfall in eastern China. Chin. Sci. Bull., 52, 33103312, https://doi.org/10.1007/s11434-007-0442-3.

_ and - 2016: Influence of soil moisture in eastern China on the East Asian summer monsoon. Adv. Atmos. Sci., 33, 151163, https://doi.org/10.1007/s00376-015-5024-8. 